\title{
SMOS: The Challenging Sea Surface Salinity Measurement From Space
}

\author{
The European Space Agency Soil Moisture and Ocean Salinity mission \\ will be the fist to measure the salinity of the Earth's surface \\ from a satellite in space.
}

\author{
By Jordi Font, Adriano Camps, Senior Member IEeE, Andrés Borges, \\ Manuel Martín-Neira, Senior Member IEeE, Jacqueline Boutin, Nicolas Reul, \\ Yann H. Kerr, Senior Member IEeE, Achim Hahne, and Susanne Mecklendurg
}

\begin{abstract}
Soil Moisture and Ocean Salinity, European Space Agency, is the first satellite mission addressing the challenge of measuring sea surface salinity from space. It uses an L-band microwave interferometric radiometer with aperture synthesis (MIRAS) that generates brightness temperature images, from which both geophysical variables are computed. The retrieval of salinity requires very demanding performances of the instrument in terms of calibration and stability. This paper
\end{abstract}

Manuscript received February 17, 2009; revised June 16, 2009 and September 8, 2009. First published November 24, 2009; current version published May 5, 2010. This work was supported by the European Space Agency with additional French and Spanish contributions. The work of J. Font and A. Camps was supported by the Spanish National R+D Plan under Grant ESP2007-65667-CO4 to the SMOS Barcelona Expert Centre on Radiometric Calibration and Ocean Salinity.

J. Font is with the Department of Physical Oceanography, Institut de Ciencies del Mar Consejo Superior de Investigaciones Científicas, 08003 Barcelona, Spain

(e-mail: jfont@icm.csic.es).

A. Camps is with the Remote Sensing Laboratory, Department of Signal Theory and Communications, Universitat Politècnica de Catalunya (UPC) and Institut d'Estudis Espacials de Catalunya/Centre de Recerca de l'Aeronàutica i de l'Espai, 08034 Barcelona, Spain (e-mail: camps@tsc.upc.edu).

A. Borges is with Construcciones Aeronauticas S.A.-Espacio,

European Aeronautic Defence and Space Company, 28022 Madrid, Spain (e-mail: Andres.Borges@casa-espacio.es).

M. Martin-Neira and A. Hahne are with the European Space Technology Centre, European Space Agency, 2200 AG Noordwijk, The Netherlands (e-mail: manuel.martin-neira@esa.int; achim.hahne@esa.int).

J. Boutin is with the Institut Pierre-Simon Laplace, Laboratoire d'Océanographie et du Climat-Expérimentation et Approches Numériques, 75252 Paris, France

(e-mail: jb@locean-ipsl.upmc.fr).

N. Reul is with the Institut Français de Recherche pour l'Exploitation de la Mer,

29280 Plouzané, France (e-mail: Nicolas.Reul@ifremer.fr).

Y. H. Kerr is with the Centre d'Etudes Spatiales de la Biosphere, 31401 Toulouse,

France (e-mail: yann.kerr@cesbio.cnes.fr).

S. Mecklenburg is with the European Space Research Institute,

European Space Agency, I-00044 Frascati, Italy (e-mail: Susanne.Mecklenburg@esa.int).

Digital Object Identifier: 10.1109/JPROC.2009.2033096 highlights the importance of ocean salinity for the Earth's water cycle and climate; provides a detailed description of the MIRAS instrument, its principles of operation, calibration, and imagereconstruction techniques; and presents the algorithmic approach implemented for the retrieval of salinity from MIRAS observations, as well as the expected accuracy of the obtained results.

KEYWORDS | Aperture synthesis; imaging; microwave radiometry; remote sensing; salinity

\section{INTRODUCTION}

Ocean salinity relates the Earth global water cycle to ocean circulation. Eighty-six percent of the total evaporation and $78 \%$ of total precipitation take place over the ocean. Salinity is modified through processes that increase or decrease the fresh water amount in the ocean surface, mainly precipitation and evaporation, but also river discharges and freezing and melting in polar regions. These changes in surface salinity are transferred to the deep ocean and spread to other regions by advection and diffusion mechanisms. This generates slight differences in dissolved salt content between the different water masses that are sufficient to play a major role in ocean dynamics and in the relationship between the ocean and the Earth's climate, e.g., by creating density gradients that drive ocean currents able to transport huge amounts of heat and modulate the climate over the continents.

Salinity is especially relevant in some key processes like the dense water formation at high latitudes, where 
high-salinity waters from the subtropical northern Atlantic Ocean are brought northwards by the Gulf Stream and then, in contact with the very cold and less saline arctic waters, form dense water masses that sink and push the three-dimensional ocean conveyor belt, the global thermohaline ocean circulation [1]. Atmospheric circulation at tropical latitudes drives fresh water evaporated from the Atlantic towards the Pacific [2] and then contributes to keep the high salinity needed for the continuity of the global thermohaline circulation. Knowing the salinity distribution at global scale and its annual and interannual variability is crucial to better understanding the ocean's role in the climate system, regulated by this circulation and water and heat fluxes between atmosphere and ocean.

The El Niño/Southern Oscillation (ENSO) is the major source of interannual climate variability, and its prediction and occurrence can have an enormous socioeconomic impact. It has been shown [3] that sea surface salinity (SSS) information would play little role in the statistical nowcast of ENSO but a significant role in 6-12 month predictions. At these lags, positive SSS anomalies off the Equator have the potential to modify the subsurface stratification of the western Pacific as they are subducted westward. In this region, the most prominent feature related to salinity is the existence of a "barrier layer" [4] that isolates the mixed layer from the entrainment of cold water from below. Thus, salinity stratification helps to preserve a warm anomaly, increases the fetch of westerly winds, and leads to the ocean-atmosphere coupled instability leading to an ENSO event [5]. On the other hand, the eastern edge of the warm pool is distinguished by a sharp SSS gradient but by a weak sea surface temperature (SST) gradient.

SSS is then a variable that not only, through its link to the evaporation minus precipitation balance, can provide valuable estimations of rainfall over the oceans, one of the less known components of the Earth's water cycle, but also is fundamental in other processes that force our global climate system.

\section{A. Sea Surface Salinity Measurements}

Until very recently, the knowledge of the global salinity distribution, and in particular its spatial and temporal variability at many scales, was really sparse. Compared to temperature, for which satellite missions have provided global coverage for more than 30 years, and in situ measurements easily done even from steaming vessels, available salinity data are far from being adequate to characterize this variability. Current compiled monthly climatologies at a $1^{\circ}$ grid resolution ${ }^{1}$ still display many ocean areas with very poor information content. In the late 1990s, the Argo program of profiling floats ${ }^{2}$ started its implementation and has reached now a worldwide deployment of more than 3000 units. This provides a quite

\footnotetext{
${ }^{1}$ http://www.nodc.noaa.gov/OC5/WOA05/pr_woa05.html.

${ }^{2}$ http://www.argo.ucsd.edu/.
}

regular coverage of the open ocean areas with temperature and salinity profiles from subsurface $(5-10 \mathrm{~m})$ to $2000 \mathrm{~m}$ depth every two weeks with an average spatial resolution of $300 \mathrm{~km}$.

However, higher spatial and temporal resolutions can only be achieved by satellite observations, and this was not attempted until now due to considerable technical challenges. A satellite can only provide measurements at the surface (SSS), where salinity is not always close to subsurface values [6], especially in tropical regions after intense rainfall when a thin fresh water surface layer can be formed. It has been shown [7] that SSS information is extremely relevant in reconstructing vertical profiles of salinity and to retrieve consistent density distributions from measurements of temperature.

SMOS, launched on November 2, 2009, is the first satellite mission addressing the salinity measurement from space [8], [9]. Information on sea surface dielectric properties (then related to salinity) is contained in the microwave emission captured by the SMOS instrument, Microwave Imaging Radiometer with Aperture Synthesis (MIRAS), a new technological concept implemented by the European Space Agency and operating at L-band, $1413 \mathrm{MHz}$.

A companion paper in this issue [10] introduces the SMOS science goals, provides an overall system and mission analysis, and, besides detailing the soil moisture component of the mission, describes the ocean salinity mapping objectives that SMOS has established, and the requirements this poses to the instrument and data processing performance. SMOS aims at contributing to the salinity remote sensing objectives as defined in 1998 by the Salinity and Sea Ice Working Group [11]: improving seasonal to interannual climate prediction, improving ocean rainfall estimates and global hydrologic budgets, and monitoring large-scale salinity events and thermohaline convection. The mission expects being able to observe barrier layer effects on tropical Pacific heat flux, halosteric adjustment of heat storage from sea level, North Atlantic thermohaline circulation, and surface freshwater flux balance, among other phenomena relevant for large-scale and climatic studies. These require an obtainable accuracy of 0.1-0.4 pss (practical salinity scale unit defined by UNESCO in 1978) over 100-300 km in 10-30 days.

\section{B. SSS Determination by L-Band Radiometry}

Spacecraft remote sensing of SSS, using microwave radiometry at low frequencies, was first proposed by Swift and McIntosh [12]. At L-band, the polarized brightness temperature $\left(T_{B}\right)$ measured by a radiometer is linked to salinity in the first centimeter of the ocean through the dielectric constant of sea water. The sensitivity increases with decreasing frequency (until around $600 \mathrm{MHz}$ ) and attenuation decreases with decreasing frequency by the atmosphere (except for heavy rain). The 1400-1427 MHz window, reserved for passive 
observations, has advantages for SSS remote sensing. This requires special care because of the low sensitivity of $\mathrm{T}_{\mathrm{B}}$ to SSS: from 0.8 to $0.2 \mathrm{~K}$ per pss, which depends on the ocean temperature, the radiometer incidence angle, and the polarization [13]. It is necessary to separate out the effects on $\mathrm{T}_{\mathrm{B}}$ from other parameters such as SST, the impact of ocean roughness, Faraday rotation, etc., as is described in Section III. The stringent requirements pose technical challenges achieving the required radiometric accuracy and stability. Finally, the low frequency involved requires the use of very large antennas to achieve a moderate spatial resolution on ground. For these reasons, only two L-band space-borne radiometers, until present, have been flown: in 1968 aboard the Cosmos 243 and in 1973 aboard Skylab S-194.

In 1995, at the Soil Moisture and Ocean Salinity Workshop organized by the European Space Research and Technology Centre, microwave radiometry at L-band was still considered the most adequate technique to remotely measure these two geophysical variables [14]. However, instead of the real aperture microwave radiometers that were considered until then, it was concluded that the most promising technique was aperture synthesis radiometry, which had successfully been demonstrated a few years earlier [15]. Le Vine et al. [16] created in 2000 an SSS map using the Electronically Steered Thinned Array Radiometer, the first one-dimensional synthetic aperture radiometer flown on an aircraft.

\section{SMOS' SINGLE PAYLOAD: THE MICROWAVE IMAGING RADIOMETER BY APERTURE SYNTHESIS (MIRAS)}

\section{A. Basic Principles}

Synthetic aperture radiometry was developed in the 1950s to obtain high-resolution radio images of celestial bodies. In 1983, LeVine and Good [17] proposed its use for Earth observation as a way to increase the angular resolution of individual antennas. As compared to real aperture

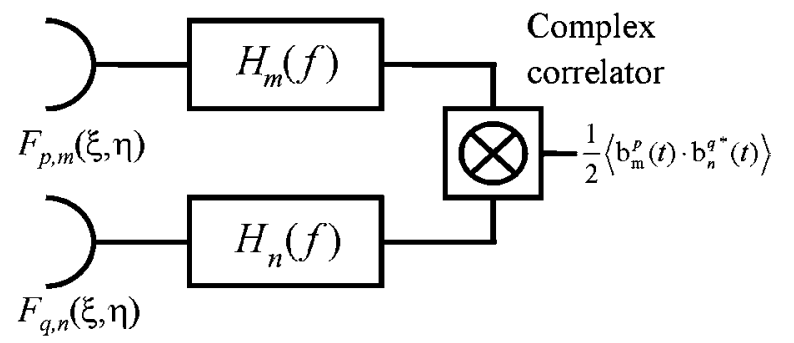

$$
\frac{1}{2}\left\langle\mathrm{~b}_{\mathrm{m}}^{p}(t) \cdot \mathrm{b}_{n}^{q^{*}}(t)\right\rangle \stackrel{\Delta}{=} \mathrm{k}_{\mathrm{B}} \cdot \sqrt{\mathrm{B}_{\mathrm{m}} \mathrm{B}_{\mathrm{n}}} \cdot \sqrt{\mathrm{G}_{\mathrm{m}} \mathrm{G}_{\mathrm{n}}} \cdot V_{m n}^{p q}\left(u_{m r}, v_{m n}\right)
$$

Fig. 1. Pair of receiving chains in an interferometric radiometer forming a baseline. radiometers, in which $T_{B}$ maps are obtained by a mechanical scan of a large antenna, in aperture synthesis radiometers, a $T_{B}$ image is formed through Fourier synthesis in a snapshot basis. A synthetic aperture radiometer measures all the cross-correlation products $\left(V_{m n}^{p q}\right)$ between the signal pairs collected by the array elements (labeled $m$ and $n$ ) at $q$ and $q$ polarizations, respectively (signals $b_{m}^{p}(t)$ and $b_{n}^{q}(t)$ in Fig. 1, which are proportional to the electric fields incident in the antennas). The total power of the scene is also measured using at least one real aperture radiometer connected to one of the antennas. For simplicity of operation, the array elements are located in a plane, and the Z-axis is orthogonal to it.

According to [18], the samples of the visibility function are given by

$$
\begin{aligned}
V_{m n}^{p q}\left(u_{m n}, v_{m n}\right) & \\
= & \frac{1}{\sqrt{\Omega_{m} \Omega_{n}}} \\
& \times \iint_{\xi^{2}+\eta^{2} \leq 1} \frac{\mathrm{T}_{\mathrm{B}}^{p q}(\xi, \eta)-\mathrm{T}_{\mathrm{rec}} \delta_{p q}}{\sqrt{1-\xi^{2}-\eta^{2}}} \cdot F_{p m}(\xi, \eta) \\
& \cdot F_{q n}^{*}(\xi, \eta) \tilde{r}_{m n}\left(-\frac{u_{m n} \xi+v_{m n} \eta}{f_{0}}\right) \\
& \cdot \exp \left(-j 2 \pi\left(u_{m n} \xi+v_{m n} \eta\right)\right) d \xi d \eta
\end{aligned}
$$

where $\mathrm{k}_{\mathrm{B}}$ is the Boltzmann's constant; $\mathrm{B}_{m, n}$ and $\mathrm{G}_{m, n}$ are the receiver's noise bandwidth and power gain; $\Omega_{m, n}$ is the solid angle of the antennas; $\mathrm{T}_{B}^{p q}(\xi, \eta) \alpha\left\langle E_{p} \cdot E_{q}^{*}\right\rangle$ is the $\mathrm{T}_{\mathrm{B}}$ of the scene at $p-q$ polarization [19], [20] $\left(E_{p}\right.$ and $E_{q}$ being the electric fields at $p$ and $q$ polarizations and \langle\rangle being the expectation operator, computed in practice as a time average); $\mathrm{T}_{\mathrm{rec}}$ is the physical temperature of the receiver (the "Corbella term"); $\delta_{p q}=1$ if $p=q$ and 0 if $F_{p, q m, n}(\xi, \eta) ; F_{p, q m, n}(\xi, \eta)$ are the normalized antenna copolar voltage patterns at $p$ and $q$ polarizations [crosspolar patterns are neglected in the simplified formulation of (1)]; $\tilde{r}_{m n}\left(-\left(u_{m n} \xi+v_{m n} \eta\right) / f_{0}\right)$ is the fringe-washing function that accounts for spatial decorrelation effects and depends on the frequency response $H_{m, n}(f)$ of the pair of elements collecting the signals being correlated; $\left(u_{m n}, v_{m n}\right) \hat{=}\left(x_{n}-x_{m}, y_{n}-y_{m}\right) / \lambda_{0}$ is the spatial frequency (baseline) that depends on the antenna position difference normalized to the wavelength $\lambda_{0}=c / f_{0} ; f_{0}$ is the center frequency of the receivers; and the direction cosines $(\xi, \eta)=(\sin \theta \cos \phi, \sin \theta \sin \phi)$ are defined with respect to the $X$ - and $Y$-axes [Fig. 4(a)].

In the MIRAS instrument, the antennas are dualpolarization patch antennas [Fig. 2(a), circles] distributed along three arms. The lightweight cost effective frontend [(LICEF); Fig. 2(b)] receivers include a polarization switch to select the antenna output. The signal is amplified, down-converted in-phase and quadrature, and sampled and converted into an optical signal that is transmitted to a 


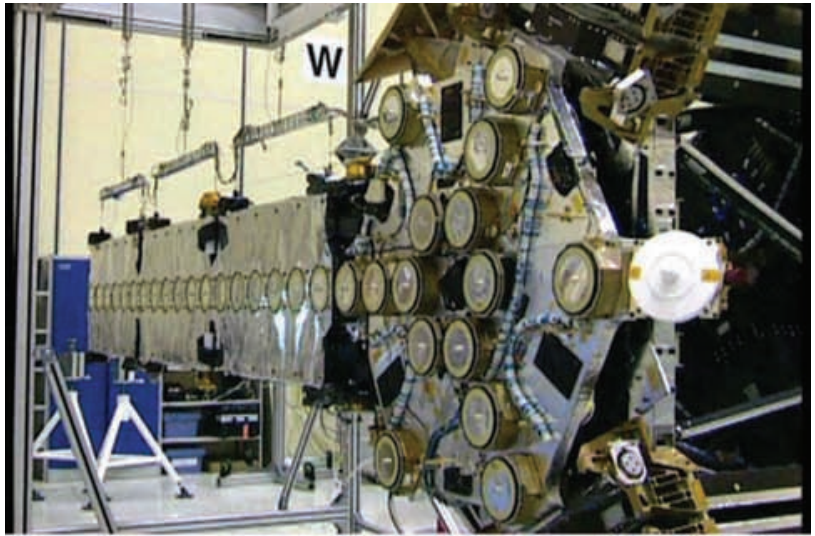

(a)

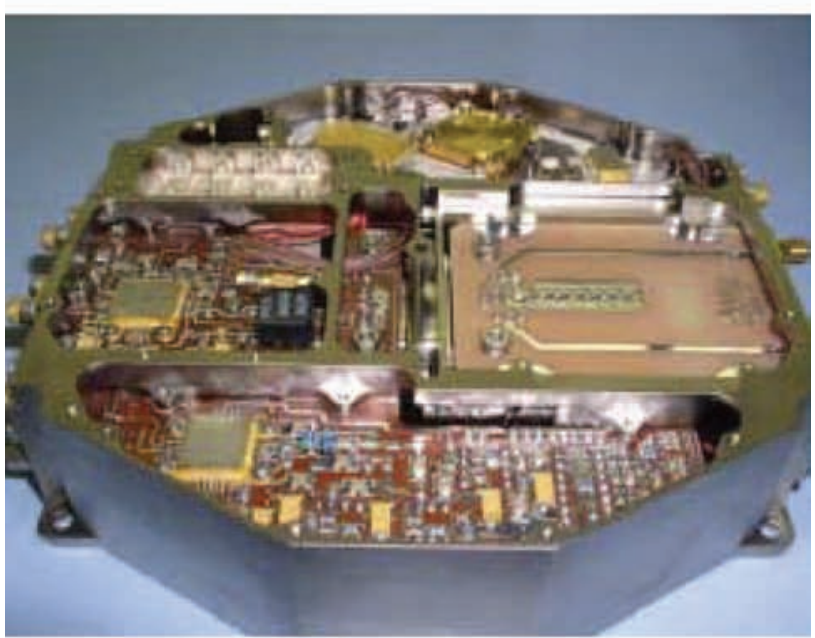

(b)

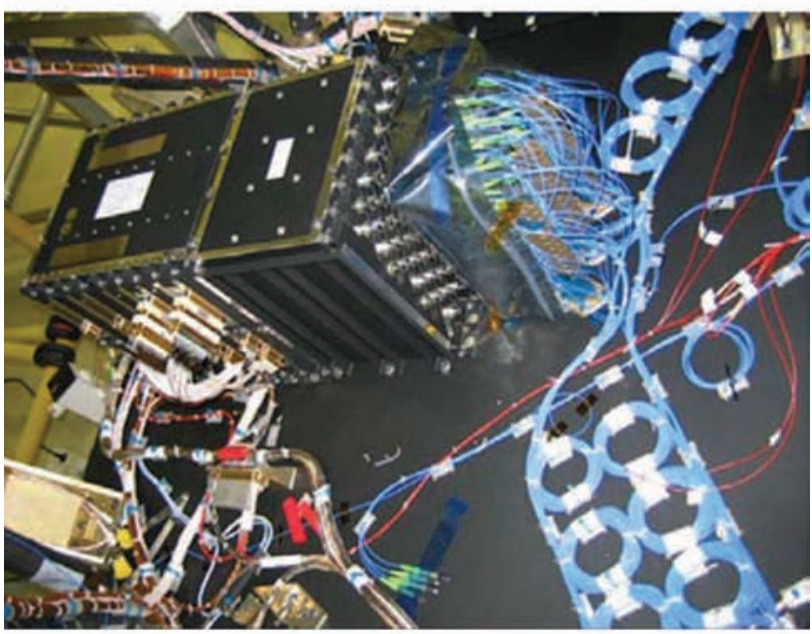

(c)

Fig. 2. (a) MIRAS hub with 15 elements and one arm formed by three segments of six elements each (total 18). (Copyright EADS-CASA Espacio.) (b) LICEF: individual receiver element of MIRAS. (Copyright Mier Comunicaciones.) (c) CCU. (Copyright EADS-CASA Espacio.) matrix of correlators [correlator and control unit (CCU); Fig. 2(c)] using equalized fiber-optic cables.

In the ideal case, when all antenna patterns are equal $\left(F_{p m}(\xi, \eta)=F_{q n}(\xi, \eta)=F(\xi, \eta)\right.$ and $\left.\Omega_{m}=\Omega_{n}=\Omega\right)$ and spatial decorrelation effects are negligible $\left(\tilde{r}_{m n} \approx 1\right)$, the relationship between the visibility samples and the modified $\mathrm{T}_{\mathrm{B}}$ [term within brackets in (2)] reduces to a Fourier transform [21]

$$
\begin{aligned}
V_{m n}^{p q}\left(u_{m n}, v_{m n}\right) & =F\left[\frac{\mathrm{T}_{\mathrm{B}}^{p q}(\xi, \eta)-\mathrm{T}_{\text {rec }} \delta_{p q}}{\sqrt{1-\xi^{2}-\eta^{2}}} \cdot \frac{|F(\xi, \eta)|^{2}}{\Omega}\right] \\
& \hat{=} F[\mathrm{~T}(\xi, \eta)] .
\end{aligned}
$$

Since the support of $\mathrm{T}(\xi, \eta)$ is the unit circle $\xi^{2}+\eta^{2} \leq 1$, it can be demonstrated [22], [23] that the optimum sampling strategy of the $(u, v)$ plane is on a hexagonal grid, instead of the rectangular one commonly used in signal and image processing. This sampling strategy allows the increase of the maximum antenna separation from $d=\lambda_{0} / 2$ to $d=\lambda_{0} / \sqrt{3}$ without suffering from aliasing effects in the image-reconstruction process, or, alternatively, for the same antenna spacing enlarging the alias-free field-of-view [Fig. 4(b)] as compared to rectangular sampling.

For a given number of elements, the array structure that provides the largest $(u, v)$ coverage (the best angular resolution) is a Y-structure, with the three arms spaced $120^{\circ}$. In MIRAS, after an optimization process of the swath width, the revisit time, the angular resolution [24], and the range of incidence angles over the Earth being imaged, it was decided to set the antenna spacing up to $d=0.875 \lambda_{0}$ with an array tilt of $32^{\circ}$ with respect to nadir. Fig. 3(a) presents a view of the MIRAS instrument deployed at Maxwell anechoic chamber for testing. This shape recalls that of the Very Large Array (VLA) radiotelescope in Socorro, NM, with 28 25-m dish antennas in a Y-array configuration [Fig. 3(b)].

In the image reconstruction, if the $\left(\xi_{r s}, \eta_{r s}\right)$ grid is selected to be the so-called reciprocal grid of the $\left(u_{m n}, v_{m n}\right)$ spatial frequencies that are sampled by the array [Fig. 4(a)], the kernel of the Fourier transform becomes separable. The visibility function sampled over a hexagonal $\left(u_{m n}, v_{m n}\right)$ grid can be processed with standard (rectangular) fast Fourier transforms [22], [23].

However, since $d>\lambda_{0} / \sqrt{3}$, the Nyquist criterion is not satisfied. The closest six replicas of $\mathrm{T}(\xi, \eta)$ (supported by the unit circle) overlap with the main one, and there is "aliasing" [Fig. 4(b)]. The alias-free field of view (AF-FOV) limited by the periodic repetition of the unit circle is, in fact, very small, but since a significant part of the aliases correspond to the cold and known sky, as it is described below, the AF-FOV can be extended (E-AF-FOV) up to the region limited by the periodic repetition of the Earth's disk [19], [22], [23], [25]. 


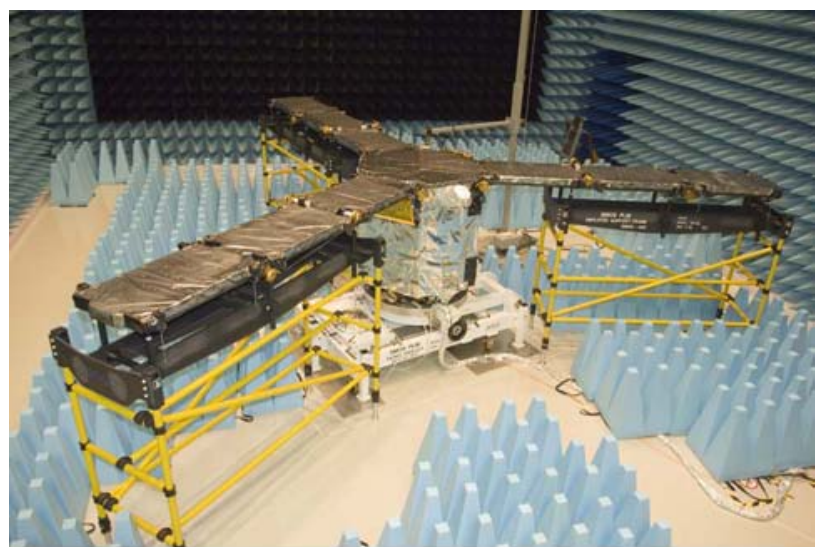

(a)

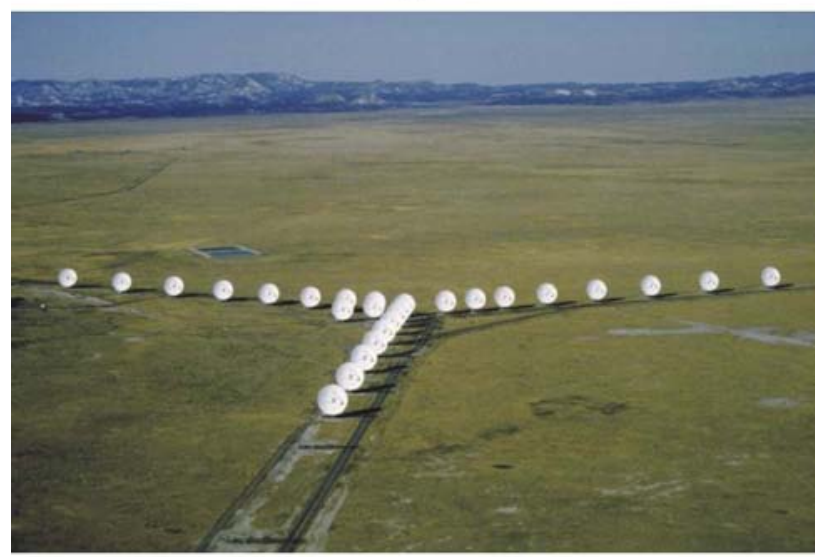

(b)

Fig. 3. (a) Full SMOS payload deployed for testing at Maxwell Electromagnetic Chamber, ESTEC (courtesy of ESA). (b) The VLA, Socorro, NM, recalls MIRAS structure.

As described in [22] and [25] the alias-free FOV extension is achieved by subtracting visibility terms corresponding to known $T_{B}$ terms, so as to reduce the angular extension of the $T_{B}$ image to be retrieved:

- $V_{\mathrm{R}}^{p q}(u, v)$ corresponding to the $-\mathrm{T}_{\text {rec }}$ in (1), which can also be measured from the so-called flat target response [26];

- $\quad V_{\text {back }}^{\text {pq }}$ corresponding to the visibilities coming from the back lobes of the antennas;

- $V_{\text {sky }}^{p q}$ corresponding to the integration of (1) in the region occupied by the L-band sky map obtained from radioastronomical measurements;

- $\bar{V}_{\text {Sun/Moon,dir/scatt }}^{p q}$ corresponding to the normalized visibilities from the direct and scattered contributions of the Sun and the Moon [25], [27];

- $\bar{V}_{\text {land }}^{p q}$ corresponding to the normalized visibility samples from the land and iced sea (which has a high $\mathrm{T}_{\mathrm{B}}$ value as well) land $(\xi, \eta)$ assumed to be at a constant $\mathrm{T}_{\mathrm{B}}$;

- $V_{\text {sea }}^{p q}$ corresponding to the visibility samples from a reference sea $(\xi, \eta)$ (e.g., $35 \mathrm{pss}, 15^{\circ} \mathrm{C}$, and

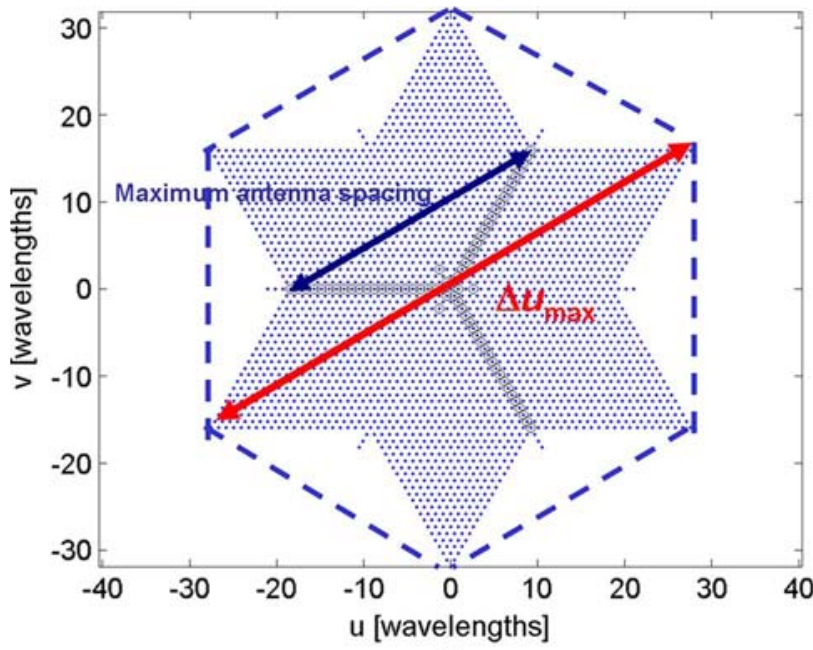

(a)

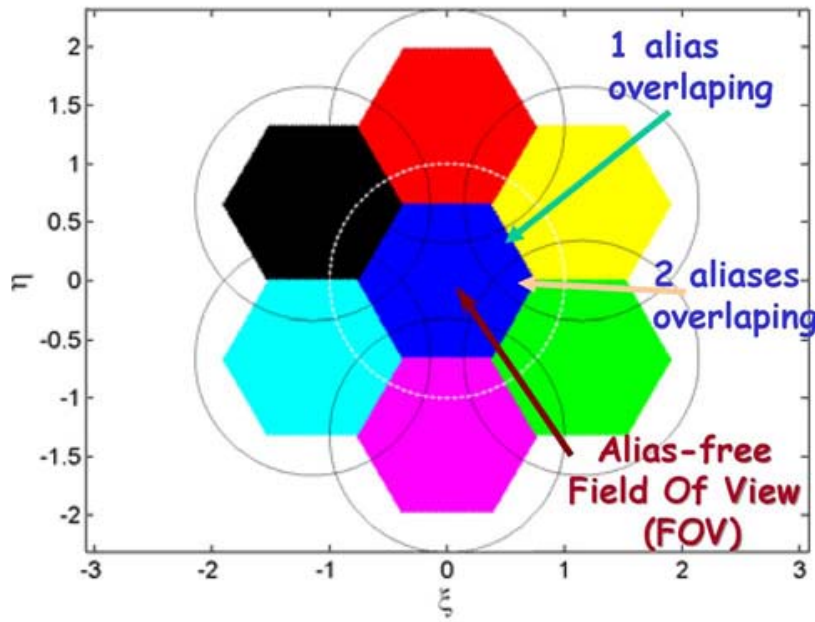

(b)

Fig. 4. (a) ( $u, v)$ spatial frequencies sampled by the SMOS Y-array (circles along lines at $+60^{\circ},+180^{\circ}$, and $\left.-60^{\circ}\right) . \Delta u_{\max }=2 \cdot$ maximum antenna spacing. (b) Periodic extension of the fundamental $(\xi, \eta)$ reciprocal grid (dark blue). Within the unit circle (white dots), the central part limited by six arcs of circumference (in black) is free from aliasing, while in some regions one or up to two aliases overlap with the main image.

$4 \mathrm{~m} / \mathrm{s}$ ) and including the incidence angle variations [25].

The "differential visibilities" constructed as ${ }^{3}$

$$
\begin{aligned}
\Delta V^{p q}(u, v)= & V^{p q}(u, v)-V_{\mathrm{R}}^{p q}(u, v)-V_{\text {sky }}^{p q}(u, v) \\
& -V_{\text {sea }}^{p q}(u, v)-T_{\text {land }}^{p q} \bar{V}_{\text {land }}(u, v) \\
& -T_{\text {Sun,dir }} \bar{V}_{\text {Sun,dir }}^{p q}(u, v) \\
& -T_{\text {Sun,dir }} \bar{V}_{\text {Sun,scatt }}^{p q}(u, v) \\
& -T_{\text {Moon,dir }} \bar{V}_{\text {Moon,dir }}^{p q}(u, v) \\
& -T_{\text {Moon,dir }} \bar{V}_{\text {Moon,scatt }}^{p q}(u, v) \\
& -V_{\text {back }}^{p q}(u, v)
\end{aligned}
$$

${ }^{3}$ Subscripts $m, n$ have been dropped since (3) and (5) refer to the whole set of visibility samples and not just to the visibility measured by a baseline. 
with the appropriate $T_{\text {land }}^{p q}$ value so that $\Delta V^{p q}(0,0)=0$, minimize the contrast of the reconstructed $T_{B}$ image, as well as the reconstruction biases originated by multiplicative errors, as recently demonstrated with real data from the SMOS demonstrator (SMOSillo, also known as AMIRAS) [28].

The image-reconstruction process then operates on $\Delta V^{p q}(u, v)$ to derive a $\Delta \mathrm{T}_{\mathrm{B}}^{p q}(\xi, \eta)$. By discretizing (1), a linear system of equations can be written in a matrix form

$$
\Delta \bar{V}^{p q}=\overline{\bar{G}} \cdot \Delta \overline{\mathrm{T}}_{\mathrm{B}}^{\mathrm{pq}}
$$

in which the $\overline{\bar{G}}$ matrix is a discretization of (1) and includes the antenna patterns, fringe-washing function, a $\Delta \xi \cdot \Delta \eta$ term for the differential area, and all the other terms in (1) different from the $\mathrm{T}_{\mathrm{B}}$ to be retrieved. Equation (4) is an underdetermined system of equations that can be solved directly by the Moore-Penrose pseudoinverse or a singular value decomposition for small/ large-size aperture synthesis radiometers [29] or by an iterative conjugate-gradient method. Lastly, the $\mathrm{T}_{\mathrm{B}}$ map is obtained as the sum of $\Delta \mathrm{T}_{\mathrm{B}}^{p q}(\xi, \eta)$ and the sea and land contributions

$$
\mathrm{T}_{\mathrm{B}}^{p q}(\xi, \eta) \hat{=} \Delta \mathrm{T}_{\mathrm{B}}^{p q}(\xi, \eta)+\mathrm{T}_{\text {sea }}^{p q}(\xi, \eta)+\mathrm{T}_{\text {land }}^{p q} \cdot \operatorname{land}(\xi, \eta)
$$

Windowing of the visibility samples is used to reduce the level of the side lobes of the synthetic beam (impulse response) at the expense of widening the beamwidth. Windowing can also be applied after the image-reconstruction process using the rectangular window so that end-users can select the optimum window for their application [30], [31]. The snapshot aliasfree $T_{B}$ image that is reconstructed in the director cosines domain is then projected into the Earth's surface (Fig. 5). As the satellite moves, multiple observations of the same pixel at different incidence angles are obtained at each polarization (Fig. 6), which is a fundamental issue in the formulation of the geophysical parameters retrievals.

\section{B. Instrument Performance}

The performance of a synthetic aperture radiometer is characterized by three parameters, which can be pixeldependent.

- The angular resolution determines the minimum angular distance between two point sources that can be resolved. In a synthetic aperture radiome-

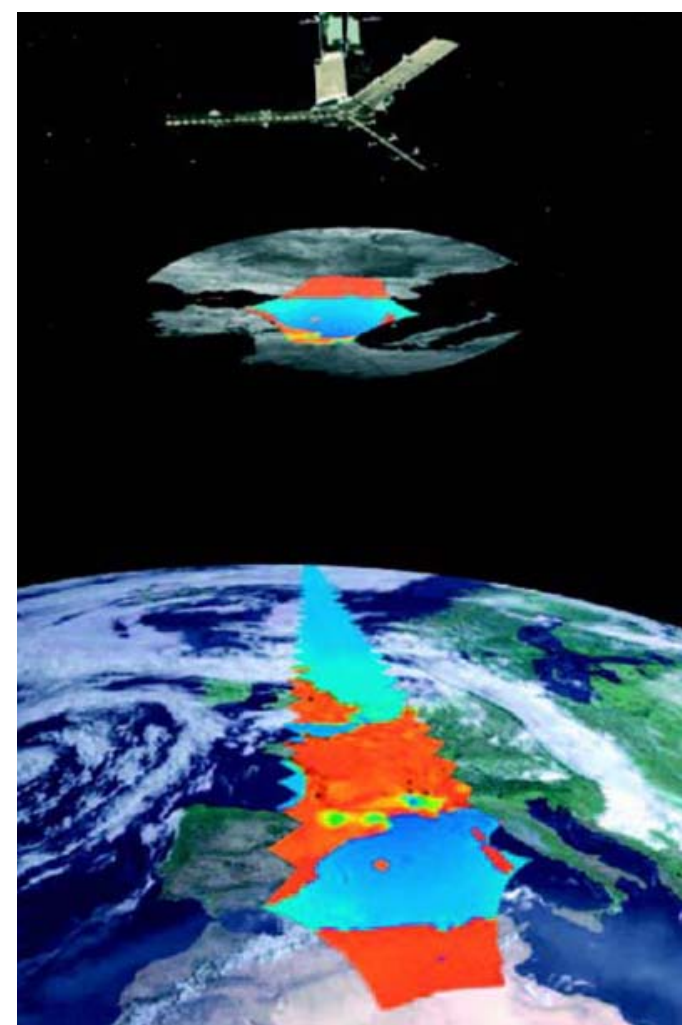

Fig. 5. Artist's view of the SMOS imaging process: director cosines images are formed through a Fourier synthesis technique and are then projected onto the Earth's surface, allowing multiple observations of the same pixel at different incidence angles (courtesy of ESA).

ter, it is basically related to the maximum antenna spacing [Fig. 4(a) and (b)], and if the visibility samples are not windowed (tapered), it is approximately $\Delta \xi_{-3 \mathrm{~dB}} \approx \pi /\left(2 \cdot \Delta u_{\max }\right)$. Out of boresight $((\xi, \eta) \neq(0,0))$, the shape of the impulse response (or point spread function in optics) suffers from a radial smearing due to spatial decorrelation effects degrading by a factor $1+W$. $\sqrt{\xi_{0}^{2}+\eta_{0}^{2}}$, where $W$ is the relative bandwidth of the system [32]. Windowing the visibility samples reduces the side-lobe level at the expense of an enlargement of the synthetic beam. The projection over the Earth of the synthetic beams enlarges and distorts with increasing distance and incidence angle (Fig. 6). Constant spatial resolution can be achieved by using a different window for each direction, at the expense of varying side-lobe levels. This technique is called strip-adaptive processing [33], [34].

- The radiometric sensitivity is the temporal standard deviation of the random errors due to noise and finite integration time. Assuming that errors in the visibility samples are uncorrelated and that all receiver parameters are the same $\left(\Omega=\Omega_{m, n}\right.$, 


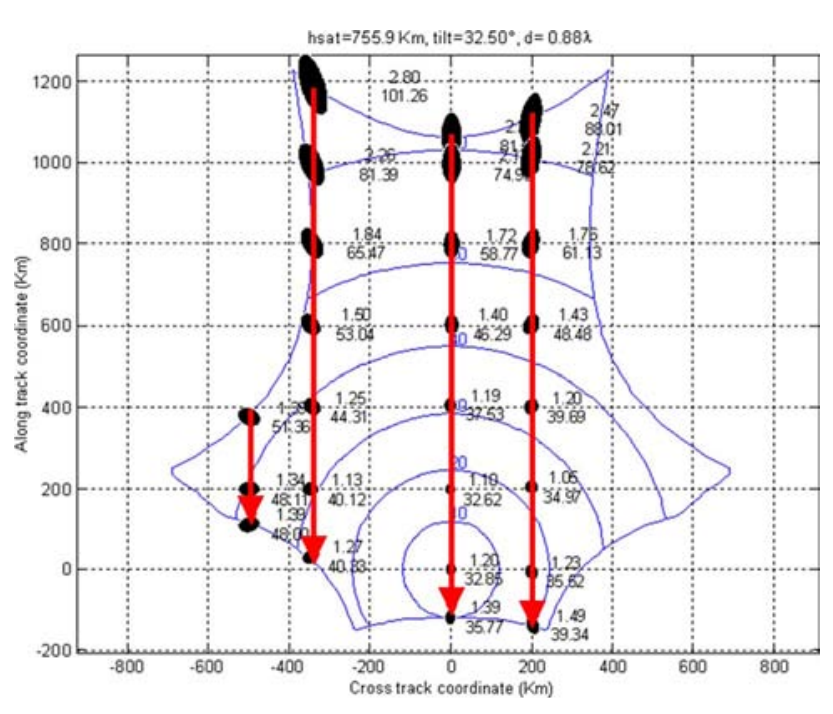

Fig. 6. Black ellipses: varying size and shape of a pixel in different positions in the FOV (marked as axial ratio and average spatial resolution in kilometers). Curved lines: constant incidence angle contours (from $0^{\circ}$ to $60^{\circ}$ ). Vertical arrows: dwell lines showing pixels entering in the upper part of the FOV and exiting in the lower part. Pixel's shape and the incidence angle vary depending on its position in the FOV, while dwell lines shorten (pixel is imaged fewer times) as the pixel under observation is farther away from satellite's ground-track. Figure computed using the SMOS End-to-End Performance Simulator (http://cassiopea.estec.esa.int/SEPS/) developed by UPC, GMV, and EADS-CASA Espacio.

$\left.\mathrm{B}=\mathrm{B}_{m, n}, \mathrm{~T}_{\mathrm{R}}=\mathrm{T}_{\mathrm{R} m, n} \ldots\right)$, the radiometric sensitivity can be computed as [22], [35]

$$
\begin{aligned}
\Delta \mathrm{T}=\Omega \cdot\left(\frac{\sqrt{3}}{2} \mathrm{~d}^{2}\right) & \cdot \frac{\mathrm{T}_{\mathrm{A}}+\mathrm{T}_{\mathrm{R}}}{\sqrt{\mathrm{B} \tau_{\mathrm{eff}}}} \cdot \alpha_{\mathrm{W}} \cdot \frac{\alpha_{\mathrm{LO}}}{\alpha_{\mathrm{F}}} \\
& \cdot \sqrt{\mathrm{N}_{\mathrm{V}}} \cdot \frac{\sqrt{1-\xi^{2}-\eta^{2}}}{|\mathrm{~F}(\xi, \eta)|^{2}}
\end{aligned}
$$

where $\Omega$ is the antenna solid angle; $\mathrm{T}_{\mathrm{A}}$ and $\mathrm{T}_{\mathrm{R}}$ are the antenna and receiver noise temperatures; $B$ is the receiver's bandwidth; $\tau_{\text {eff }}$ is the effective integration time, which depends on the correlator type $\left(\tau_{\text {eff }}=\tau / 2.46\right.$ or $\tau / 1.82$ for 1 bit two-level digital correlators with sampling frequency equal to $2 \cdot \mathrm{B}$ or $4 \cdot \mathrm{B}$, respectively [36]); $\alpha_{\mathrm{W}}, \alpha_{\mathrm{LO}}$, and $\alpha_{\mathrm{F}}$ are parameters that depend on the window $\left(\alpha_{\mathrm{W}}=1\right.$ for a rectangular window and $\alpha_{\mathrm{W}}=0.45$ for a Blackman window), the type of demodulation $\left(\alpha_{\mathrm{LO}}=1\right.$ or 1.41 for single or double sideband receivers), and the shape of the frequency response $\left(\alpha_{\mathrm{F}}=1 \ldots 1.19\right.$ for rectangular or Gaussian filters); and $\mathrm{N}_{\mathrm{V}}$ is the total number of $\left(u_{m n}, v_{m n}\right)$ points sampled by the array $\left(\mathrm{N}_{\mathrm{V}}=6 \mathrm{~N}_{\mathrm{EL}}^{2}+6 \mathrm{~N}_{\mathrm{EL}}+1=2773\right.$, with $\mathrm{N}_{\mathrm{EL}}=21$ being the number of antenna elements in each arm of the Y-array) [22], [23]. Out of boresight, the radiometric sensitivity degrades with the inverse of the obliquity factor and the normalized antenna radiation pattern [(6)]. Actually, there is some weak correlation between the errors in the visibility samples. This correlation translates into an error map that is image-dependent. The radiometric sensitivity follows the $T_{B}$ in a nonlinear way [37], [38] (see Table 1).

- The radiometric accuracy in a synthetic aperture radiometer must be split in two terms: the spatial average of the systematic errors (instrumental errors) appears as a radiometric bias (scene bias) in the whole $T_{B}$ image and their spatial standard deviation is the radiometric accuracy (pixel bias). The different instrumental error sources can be grouped as antenna errors, affecting each pixel in the scene in a different way, receiver amplitude and phase errors that can be assigned to each element forming the baseline, and baseline errors that can only be assigned to the pair of elements forming the baseline [39], [40].

The detailed error model of a baseline in a correlation radiometer as MIRAS is given by [39]. It can be written in a very simplified form as

$$
\mu_{m n}=c_{m n} \cdot \overline{\bar{Q}} \cdot V_{m n}+\text { offset }
$$

where $c_{m n}$ is a complex gain term, $\overline{\bar{Q}}$ is the quadrature matrix that accounts for in-phase quadrature errors and offset accounts for correlations' offsets, due to correlators' own offset, leakage of the local oscillator or other correlated signals, or, in the case of 1 bit two-level digital correlators, to threshold errors in the samplers.

These errors are calibrated by internal and external calibration. Due to the large mass, volume, and moment of inertia, internal calibration by injection of noise from a single source in the hub whose output is distributed to all receivers was discarded. Instead, distributed noise injection from a number of noise sources injecting noise to smaller groups of receivers was proposed [41]. This

\begin{tabular}{|c|c|c|}
\hline & Required & Measured \\
\hline Systematic error & $\begin{array}{l}1.5 \mathrm{KRMS}\left(0^{\circ}\right) \\
2.5 \mathrm{KRMS}\left(32^{\circ}\right)\end{array}$ & $\begin{array}{l}0.9 \mathrm{~K} \mathrm{RMS} \\
\text { in AF-FOV }\end{array}$ \\
\hline $\begin{array}{l}\text { Land }\left(\mathrm{T}_{\text {Bland }}=220 \mathrm{~K}\right) \\
\text { Radiometric sensitivity }\end{array}$ & $\begin{array}{l}3.5 \mathrm{~K} \mathrm{RMS}\left(0^{\circ}\right) \\
5.8 \mathrm{~K} \text { RMS }\left(32^{\circ}\right)\end{array}$ & $\begin{array}{c}2.23 \mathrm{~K} \mathrm{RMS}\left(0^{\circ}\right) \\
3.95 \mathrm{~K} \mathrm{RMS}\left(32^{\circ}\right)\end{array}$ \\
\hline Ocean $\left(T_{\text {Bocean }}=150 \mathrm{~K}\right)$ & $2.5 \mathrm{KRMS}\left(0^{\circ}\right)$ & $1.88 \mathrm{KRMS}\left(0^{\circ}\right)$ \\
\hline Stability (1.2 s int.) & 4.1 K RMS $\left(<32^{\circ}\right)$ & $4.03 \mathrm{~K}$ RMS \\
\hline Stability (long int.) & $0.03 \mathrm{~K}$ & $<0.02 \mathrm{~K}$ \\
\hline
\end{tabular}
technique consists of the injection of two noise levels

Table 1 MIRAS Radiometric Requirements and Performances 


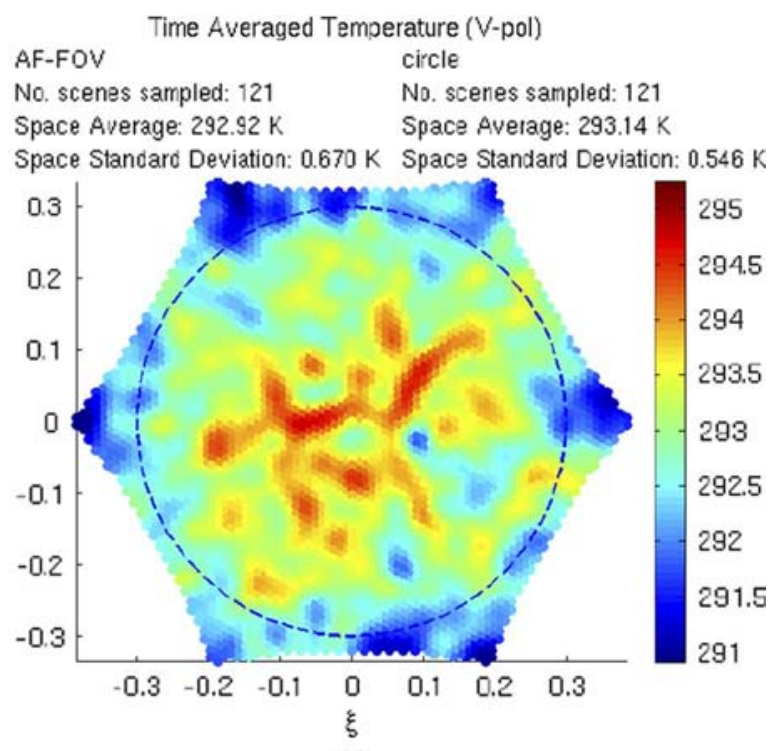

(a)

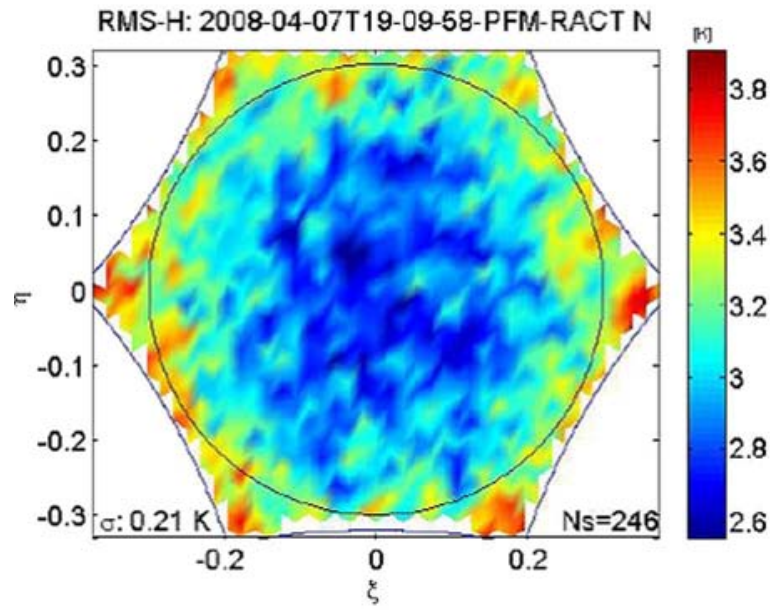

(b)

Fig. 7. (a) Systematic radiometric error (including bias, drift, periodic, and other errors such as thermoelastic effects). Worst polarization (IVT): $0.67 \mathrm{~K}$ rms spatial ripple. A verage $\mathrm{T}_{\mathrm{B}}$ at vertical and horizontal polarizations is 293.1 and $293.7 \mathrm{~K}$, respectively. Physical temperature of microwave absorbers is $293.7 \mathrm{~K}$. (b) Radiometric sensitivity at boresight $=2.6 \mathrm{~K}$ (worst polarization; EMC empty chamber test).

from different sources distributed in the hub and along the arms to smaller groups of receivers, with some common receivers among groups, and an uncorrelated noise source in each receiver. In this way, separable phase and amplitude error terms can be calibrated, but not all the nonseparable ones - only those from baselines formed by receivers sharing the same noise source. However, nonseparable errors can be minimized if receivers' frequency response mismatches are kept to a minimum and satisfy strict predetermined deviation masks [42]. A detailed description of the internal calibration procedures in MIRAS is given in [43].
Differences between antenna voltage patterns affect the imaging algorithm, which will no longer be a Fourier transform [(2)] and require an accurate characterization on-ground and perfectly known scenes (external targets) to be calibrated [25], [44]. The external calibration consists of measuring external known targets (the homogeneous galaxy pole, preferably) to calibrate the three redundant polarimetric noise injection radiometers (used to measure the Stokes elements $\left.{ }^{4} \mathrm{~V}(0,0) \equiv \mathrm{T}_{\mathrm{A}}\right)$ and to measure the so-called flat target response to be applied in the flat target transformation [26], [28].

Fig. 7(a) and (b) shows the measured instrument performance during the image validation tests (IVTs) at ESTEC Maxwell Chamber (EMC). MIRAS was placed in a large anechoic chamber [Fig. 3(a)] looking to microwave absorbers at 293.7 K physical temperature.

The worst case systematic error can be computed as the root mean square ( $\mathrm{rms}$ ) value of the difference between the physical temperature of the absorber and the average measured $\mathrm{T}_{\mathrm{B}}$ in the FOV, plus the $0.67 \mathrm{~K} \mathrm{rms}$ spatial ripple [Fig. 7(a)]: $\sqrt{(293.7 \mathrm{~K}-293.1 \mathrm{~K})^{2}+(0.67 \mathrm{~K})^{2}}=0.9 \mathrm{~K}$.

The worst case radiometric sensitivity is $2.6 \mathrm{~K}$ [Fig. 7(b)], which corresponds to a system temperature of $513.7 \mathrm{~K}\left(\mathrm{~T}_{\mathrm{A}}=293.7 \mathrm{~K}, \mathrm{~T}_{\mathrm{R}}=220 \mathrm{~K}\right)$. The boresight sensitivity when imaging the ocean or the land (reference antenna temperatures $\mathrm{T}_{\mathrm{A} \text {,ocean }}=150 \mathrm{~K}, \mathrm{~T}_{\mathrm{A} \text {,land }}=220 \mathrm{~K}$ ) can be readily obtained $[(6)]$ by scaling the measured radiometric sensitivity by the ratio of the system temperatures: $\Delta \mathrm{T}_{\text {ocean }}=1.87 \mathrm{~K}$ and $\Delta \mathrm{T}_{\text {land }}=2.23 \mathrm{~K}$. Out of boresight, the radiometric sensitivity degrades, and at $32^{\circ}$, a 1.64 amplification factor applies. Table I summarizes the MIRAS radiometric requirements and performances expressed in rms of $\mathrm{T}_{\mathrm{B}}$ as measured in May-June 2007 at EMC.

The stability at $1.2 \mathrm{~s}$ was calculated as the rms combination of the systematic error and the $1.2 \mathrm{~s}$ radiometric sensitivity, at the edge of the FOV $\left(32^{\circ}\right)$. Its maximum value over a period of six days is given in Table I. The stability at long integration was calculated as the standard deviation between the difference of antenna temperatures measured by the six noise-injection radiometers channels available in the MIRAS instrument and over an observation period of six days.

The values presented in Table I provide the worst case, whenever several measurements were available.

\section{SSS RETRIEVAL WITH SMOS}

The basic algorithmic approach selected for SSS retrieval from SMOS radiometric measurements [45], [46] is based on an iterative convergence scheme that compares the

\footnotetext{
${ }^{4}$ Equation (1) applies to a pair of receivers only, and cannot be applied to compute $V(0,0)$, which is measured by three real aperture noise injection radiometers, so that $V^{p q}(0,0) \equiv \mathrm{T}_{\mathrm{A}}^{\mathrm{pq}}: V^{v v}(0,0) \equiv \mathrm{T}_{v}$, $V^{v h}(0,0) \equiv \mathrm{T}_{\mathrm{A}}^{v h}=\left(\mathrm{T}_{3}+j \cdot \mathrm{T}_{4}\right) / 2, V^{v h}(0,0) \equiv \mathrm{T}_{\mathrm{A}}^{v h}=\left(\mathrm{T}_{3}+j \cdot \mathrm{T}_{4}\right) / 2$.
} 
measured values with those provided by an L-band forward model of the sea surface emission. This model uses a guessed salinity that can be adjusted until obtaining an optimal fit with the radiometric measurement.

MIRAS allows at each satellite overpass to measure a two-dimensional image of the ocean surface under a wide range of incidence angles, then provide a series of different $T_{B}$ values corresponding to a single salinity value at a fixed ocean location. This overdetermination is used to reduce the measurement noise and to adjust several geophysical variable parameters that characterize the sea state (for example, sea surface temperature, wind speed, significant wave height) and are also included in the forward model, in addition to SSS, in the iterative minimization process. Besides the low sensitivity of $\mathrm{T}_{\mathrm{B}}$ to salinity, three other major problems make the SMOS determination of SSS a real challenge.

1) the instrument limitations (radiometric noise, calibration stability, image reconstruction techniques);

2) the need for precise and simultaneous auxiliary information on the sea surface properties (temperature, roughness, etc.) to be estimated from external sources;

3) the accuracy of the forward model of the sea surface emissivity to be used in the iterative convergence.

The forward model or geophysical model function has to simulate the $T_{B}$ that reaches the radiometer antenna from the emitting top ocean layer. This depends on sea water characteristics plus geometry of the ocean surface (roughness), the possibility of other external L-band radiation being scattered on the roughened surface, and the transformation the overall emission leaving the surface suffers until reaching the antenna.

The L-band emissivity of a flat sea as a function of temperature, salinity, viewing angle, and polarization has been quite well modeled since the late 1970s [47], as verified by new laboratory measurements in the last years [48], [49] (although there are still some differences, especially in the imaginary part), but the different processes that impact on the emission of a roughened surface were not fully described or considered in the several theoretical formulations available at the moment of starting the development of SMOS algorithms [50]. It has been necessary to design and implement several new components of the L-band forward model for the SMOS Level 2 Ocean Salinity Processor (L2OP) [46]. This includes a series of tests to sort out, in every SMOS snapshot (level 1c data), $\mathrm{T}_{\mathrm{B}}$ values that may be wrong due to being contaminated by land or sea ice emission, radiofrequency interference (RFI), sun and moon glint, or heavy rain attenuation, and several modules to take into account the different effects as explained below (Fig. 8).

In a first step, the polarized $\mathrm{T}_{\mathrm{B}}$ of the sea $T_{h, v}^{\text {sea }}$ can be decomposed in two terms: the "flat sea" contribution (with typical values of $70-150 \mathrm{~K}$ depending on the polarization and incidence angle) and a deviation with respect to it that can reach up to $10 \mathrm{~K}$. The deviation term $\Delta T_{h, v}(\theta$, param $)$ depends on the incidence angle and a parameterization of the surface roughness by means of variables such as wind speed, significant wave height, wave age, atmospheric stability, etc. [51]. We can consider that at first order, this deviation is independent of SST and SSS and can be modeled through theoretical formulations (statistical description of the sea surface plus electromagnetic scattering model) [52], [53] or empirical approximations [54]

$$
\begin{gathered}
T_{h, v}^{\text {sea }}(\theta, \operatorname{SST}, \mathrm{SSS}, \text { param }) \\
\approx\left(1-\Gamma_{h, v}\left(\theta, \varepsilon_{r}(\mathrm{SST}, \mathrm{SSS})\right)\right) \\
\cdot \operatorname{SST}+\Delta \mathrm{T}_{h, v}(\theta, \text { param })
\end{gathered}
$$

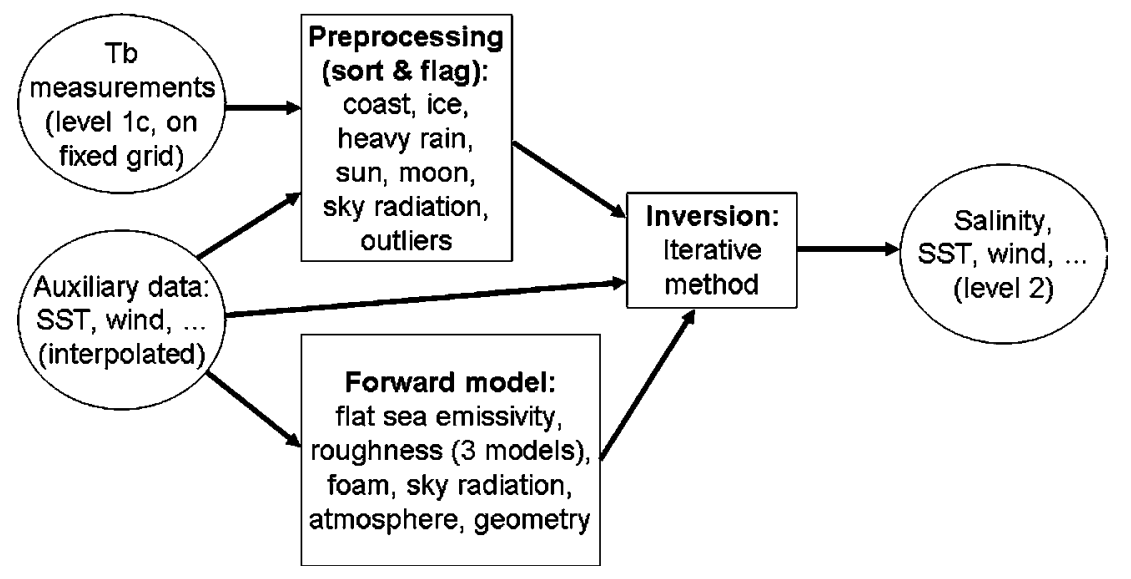

Fig. 8. Block diagram of the SMOS SSS retrieval processor. 
In (8), $\Gamma_{h, v}\left(\theta, \varepsilon_{r}(\mathrm{SST}, \mathrm{SSS})\right)$ is the Fresnel reflectivity that through the dielectric constant depends on SSS and SST.

The effect of surface roughness is the main geophysical source of error in SMOS salinity retrieval. The changes in the ocean $T_{B}$ produced by the sea state can be of the same order as the salinity-induced change itself, as the impact of the roughness increase caused by a $10 \mathrm{~m} / \mathrm{s}$ wind is roughly equivalent to the impact of a modification of SSS by 5 pss at moderate SST. The SMOS L2OP implements three roughness correction model approaches [46] as alternatives to be evaluated and tuned during the mission calibration and validation phase. At present, the available data reporting rough sea surface emissivity dependencies with wind speed do not allow to discriminate the best adapted correction between these three models of the roughness impact [45]. All the auxiliary data required for these models will be obtained operationally from the European Centre for Medium range Weather Forecast (ECMWF) and then preprocessed to generate derived variables and interpolate them at the required spatial and temporal grids.

When high winds generate foam, there is an increase of the $T_{B}$, which is a function of the sea surface fraction covered by foam and the $T_{B}$ of the sea foam. Several controlled measurements [55], [56] indicate a foam-induced emissivity in good agreement with the Reul-Chapron [57] model specifically developed for SMOS under some conditions. Other effects that modify sea $T_{B}$ are those of rain and oil slicks that can change the sea surface waves spectrum, which affects $T_{B}$. A summary of these effects can be found in [58].

Before comparing the modeled and measured $\mathrm{T}_{\mathrm{B}}$ in the iterative process, it is necessary to add to the sea surface emission the other components of the geophysical model function mentioned above. It is also necessary to geometrically transform the modeled polarized $\mathrm{T}_{\mathrm{B}}$ from the Earth reference frame (where the forward model has been applied) to the antenna reference frame (where measurements are done). Several atmospheric effects (upwelling radiation, downwelling radiation scattered over the sea surface, atmospheric/ionospheric losses) are sufficiently well modeled [59]

$$
\begin{aligned}
\mathrm{T}_{\mathrm{B} \text { TOA }}=\mathrm{T}_{\mathrm{Bs}} \exp \left(-\tau_{\mathrm{atm}}\right) & +\mathrm{T}_{\mathrm{B} \text { up }} \\
+ & +\Gamma \cdot \mathrm{T}_{\mathrm{B} \text { down }} \exp \left(-\tau_{\text {atm }}\right)
\end{aligned}
$$

where $T_{B}$ TOA is the $T_{B}$ at the top of atmosphere, $\mathrm{T}_{\mathrm{Bs}}=\mathrm{T}_{h, v}^{\text {sea }}$ the upwelling $\mathrm{T}_{\mathrm{B}}$ from the surface [(8)], $\mathrm{T}_{\mathrm{B} \text { up }}$ the $\mathrm{T}_{\mathrm{B}}$ self-emitted by the atmosphere upwards and attenuated along upward path, and $T_{B}$ down the $T_{B}$ selfemitted by the atmosphere downwards and attenuated along downward path. $\tau_{\text {atm }}$ is the equivalent optical thickness of the atmosphere and $\Gamma$ is the surface reflectivity indicated in (8). Equation (9) applies separately to both polarizations.

The polarization mixing (Faraday rotation) due to the electromagnetic wave propagation through the ionosphere in the presence of the geomagnetic field [60], [61] can be either modeled from the knowledge of the ionospheric total electron content (TEC) or avoided by using the first Stokes parameter $\mathrm{I}=\mathrm{T}_{h}+\mathrm{T}_{v}$ instead of both polarizations separately in the retrieval. This alternative option presents several other advantages, such as the cancellation of geometric rotation effects when changing the reference basis from surface to antenna planes. It also reduces the uncertainties in the $\mathrm{T}_{\mathrm{B}}$ associated to angular dependencies of the sea water dielectric constant model and in the roughness correction term, even though the number of observables is halved [62].

Radiation by celestial sources illuminating the ocean surface that are further reflected (through scattering produced by the surface roughness) towards the radiometer has to be taken into account. The $\mathrm{T}_{\mathrm{B}}$ of the source brightness, ranging from 2 to $7 \mathrm{~K}$, can be estimated from sky surveys. The surface-level scattered signals are computed through a proper weighting of the sky $\mathrm{T}_{\mathrm{B}}$ illuminating the considered Earth target by the rough sea surface bistatic scattering coefficients estimated at that point [63], [64]. Reflected solar radiations are extremely intense at L-band $\left(10^{5}\right.$ to $\left.10^{7} \mathrm{~K}\right)$, and their contribution needs to be accounted for [27], [65]. With the SMOS orientation, the Sun is present in $97 \%$ of the snapshots. Therefore, Sun cancellation algorithms [27] had to be developed to estimate the $T_{B}$ coming from the Sun and subtract it as described in (3). The few affected grid points and angular measurements will be discarded for salinity retrieval instead of attempting a correction [45].

The part of the retrieval algorithm that performs the iterative comparison between model and data uses a cost function to be minimized

$$
\chi^{2}=\sum_{n=1}^{N} \frac{\left[T_{\mathrm{B} n}^{\text {meas }}-T_{\mathrm{B} n}^{\bmod }\left(\theta_{n}, P_{i} \ldots\right)\right]^{2}}{\sigma_{\mathrm{TB} n}^{2}}+\sum_{i=1}^{M} \frac{\left[P_{i}-P_{i 0}\right]^{2}}{\sigma_{P i 0}^{2}}
$$

based on the difference between measured and modeled $\mathrm{T}_{\mathrm{B}}$ in the antenna reference frame and incorporating reference values $\left(P_{i 0}\right)$ and associated uncertainties $\left(\sigma_{P i 0}^{2}\right)$, as weights, for the external geophysical parameters $\left(P_{i}\right.$, including SSS) that provide information on the sea state conditions and that will be themselves adjusted during the convergence process. For every pixel on the SMOS FOV, the comparison is made using all $N$ available angular measurements acquired in consecutive satellite snapshots. The number of measurements of each pixel depends on the pixel's cross-track distance to the satellite ground-track. As this distance increases, the pixel is imaged fewer times; the 
angular variation is reduced (Fig. 6) and the instrument's noise increases, which translates into a degraded performance in terms of the quality of the retrieved parameters. An important problem is that up to $100-200 \mathrm{~km}$ from the coast, the retrieval will be considerably degraded by radiometric contamination from land [66], [67].

The cost function can also be formulated in terms of the first Stokes parameter (as previously pointed out) or in terms of $T_{B}$ in the Earth reference frame. However, in this case, in the dual-polarization mode, many pixels have to be discarded since they are affected by large noise amplification in regions close to the singularities of the transformation from the antenna to the Earth reference frames. This situation can be avoided using the fullpolarimetric mode, at the cost of larger noise everywhere in the image.

Several of the components described above as steps of the SSS retrieval procedure are specific to the observational approach selected for SMOS, namely, aperture synthesis. This technique has a main weakness in the need of performing the complex image reconstruction described in Section II and the errors this can introduce. However, it has remarkable strengths compared to measurements made by real aperture antennas. We have highlighted above the multiangular observation of a single spot that allows taking advantage of the sensitivity of $T_{B}$ to the incidence angle to increase the robustness of the inversion. Another fundamental feature is the high angular resolution that allows imaging pixels on the order of $30 \mathrm{~km}$ and, as a consequence, identifying different elements within the FOV, like the Sun, that can then be removed from the image.

A detailed description of the mentioned different components of the SSS retrieval algorithm (Fig. 8) as they have been implemented in the SMOS L2OP can be found in [46]. The processor was designed for ESA by a team formed by ICM-CSIC (Font), LOCEAN (Boutin) and IFREMER (Reul).

The processor is prepared to make the retrieval under the two observation modes that MIRAS can operate: dual polarization and full polarization. During SMOS commissioning phase (six months after launch), both polarization modes will be tested to decide what will be used in regular operations. As polarized measurements are made in consecutive $1.2 \mathrm{~s}$ snapshots, dual polarization provides more data and, in consequence, a higher noise reduction. However, acquiring the cross-polarized components in the so-called full-polarimetric operation mode can provide useful additional information, e.g., to avoid the singularities of the transformation from the antenna to the Earth reference frame, to allow improved RFI detection, to eventually identify azimuthal signals, or to estimate the Faraday rotation. The different approaches presented will be tested during the SMOS commissioning phase. If acquiring fully polarized data does not imply a significant loss of SSS retrieval quality, it could be kept as acquisition mode during the SMOS operational phase for further investigation on using the cross-polar information in improving the retrieval, once the basic SMOS SSS L2 objectives are achieved.

The validity of retrievals, and in particular the accuracy of estimators, depends on the overall reliability of radiometric measurements, of auxiliary data, and of direct models used in the retrieval algorithm. When implementing a Bayesian approach with a convergence loop, the influence of the prior values (initial conditions) depends on the theoretical uncertainty put on these values. In case this uncertainty is large with respect to the uncertainty claimed on the a priori values, a bias may be generated by errors in a priori values. Actually, the direct models used in the retrieval are both slightly nonlinear and approximated. Hence, one may expect retrieval biases as well as underestimation of the theoretically estimated retrieval uncertainties. This will require additional processing to mitigate these biases and improve the uncertainties, for example, by using external data like in situ salinity measurements or collocated SSS observations by the U.S.-Argentinean Aquarius/SAC-D mission that is expected to be launched in late 2010 and will operate a real aperture L-band radiometer [68], [69].

Idealized tests of the L2OP performance have been done under different configurations and environmental conditions. Simulated scenes, either with constant SST, SSS, and wind or including different gradients, are used to compute the polarized $\mathrm{T}_{\mathrm{B}}$ in the SMOS swath along an orbit by means of the forward model with one of the three roughness options. Then radiometric noise is added according to the expected MIRAS performance (Table 1), and the processor is run with different errors and biases for the auxiliary parameters.

These tests show that the retrieved SSS values from one satellite overpass (spatial resolution of the order of $40 \mathrm{~km}$ and temporal resolution three days) will be affected by considerable noise, both from radiometric origin and from uncertainties in the algorithm and auxiliary data $\left(\sigma_{\mathrm{SST}}=1{ }^{\circ} \mathrm{C}, \sigma_{\mathrm{WS}}=1.5 \mathrm{~m} / \mathrm{s}, \sigma_{\mathrm{TEC}}=5 \mathrm{TECu}\right.$ are used as nominal uncertainties in the simulations, with SSS unconstrained). This L2 error is on the order of $0.5-0.7 \mathrm{pss}$ in the center of the swath and degrades to about 1.5 on its borders (Fig. 9). These results improve with high SST scenes but can be as bad as 1.2 pss (center) and 2.4 pss (borders) for SST $=5{ }^{\circ} \mathrm{C}$. Introducing biases on the auxiliary parameters produces also a bias on the retrieved SSS that can reach up to $0.7 \mathrm{pss}$ (center) and 0.9 pss (border) when WS is biased by $2 \mathrm{~m} / \mathrm{s}$.

A more realistic simulation for a homogeneous scene, using, e.g., the different measured antenna patterns for all MIRAS elements, has been performed in a recent complete SMOS system end-to-end performance test (internal ESA document for SMOS Flight Acceptance Review, May 2009). Starting from the instrument performances as indicated in Fig. 7 and Table 1, and using the selected 
SMOS flight configuration plus all the components and corrections included in level 1 and level 2 processors, this study shows that the extended alias-free field of view may not be usable for SSS retrieval due to excessive noise and bias (Fig. 10) partly caused by contamination from sun glint. The expected overall uncertainty in salinity retrieval as estimated when the SMOS mission was proposed (1.2 pss from a single orbit) can be degraded by almost $50 \%$.

To reduce the uncertainty and be closer to the mission requirements in terms of salinity maps accuracy (0.10.2 pss, in 100-200 km grid, every 10-30 days), it will be necessary to perform spatiotemporal averages of level 2 products [70], [71] in the generation of SMOS level 3 products (global gridded maps) suitable for large-scale and climatic studies.

A salinity error budget analysis has been performed to evaluate the extent of the impact of different variables and parameterizations (instrumental, external noise sources, and geophysical errors) in the level 3 SSS accuracy [72]. Simulations were made in an open ocean $10^{\circ} \times 10^{\circ}$ region by using SMOS End-to-End Performance Simulator (SEPS)derived $T_{B}$ maps showing the realistic features induced by the image reconstruction algorithm, such as biases and radiometric errors. Different combinations of configurations and auxiliary data uncertainties were analyzed. It was concluded that, with the expected accuracy of the ECMWF data and using a constrained SSS in the cost function (an option not implemented by now in the L2OP), an average of SMOS L2 products over 30 days and $2 \times 2^{\circ}$ boxes would generate an SSS L3 product with an error of 0.22 pss, very close to the mission requirements, in dual-polarization and in the antenna reference frame. Of course these are theoretical estimations that will be revisited when real data start to be

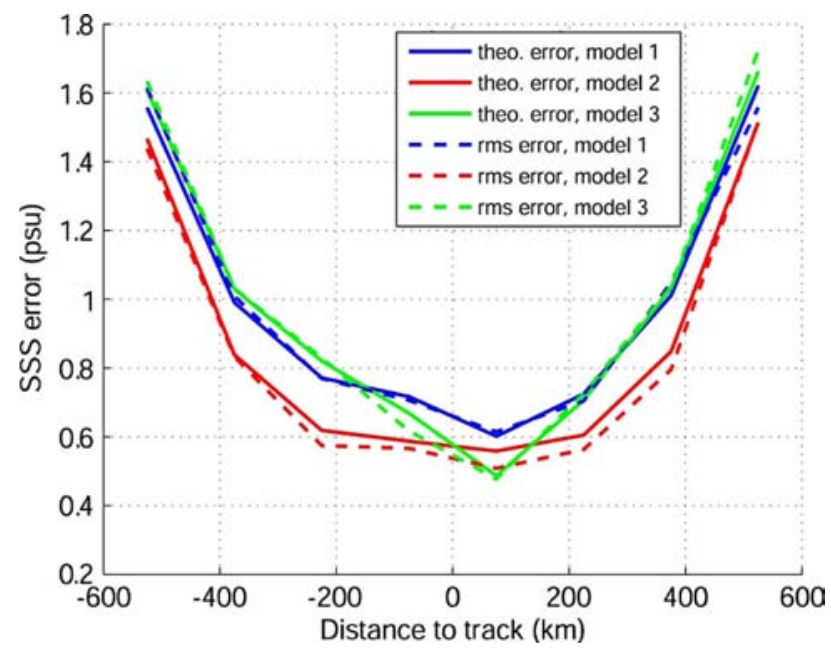

Fig. 9. Theoretical error (solid lines) and rms error (dashed lines) on the retrieved SSS as a function of distance to track for the three roughness models implemented in the L2OP. The simulation is performed in dual-polarization mode on an homogeneous scene with SSS $=35$ pss, SST $=15^{\circ} \mathrm{C}$, WS $=7 \mathrm{~m} / \mathrm{s}$ (from [46]).

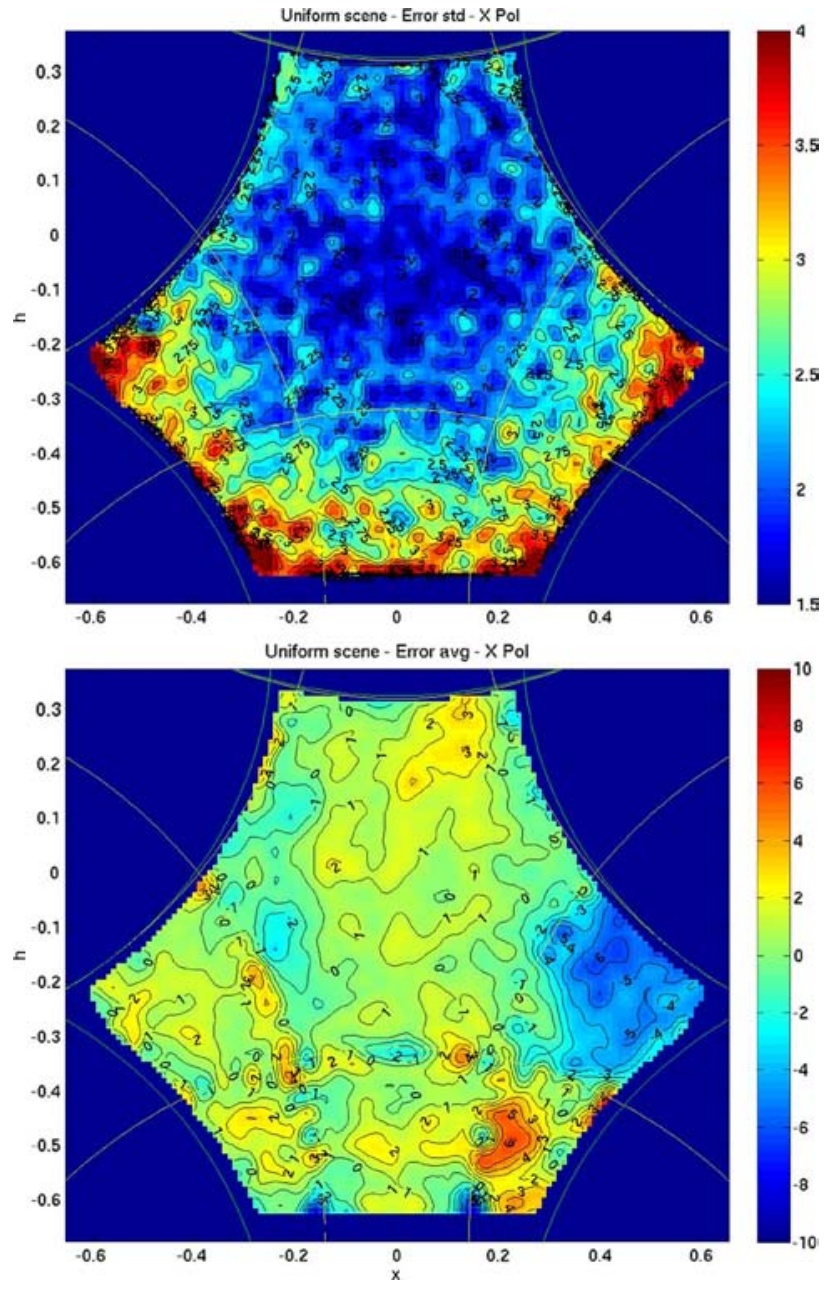

Fig. 10. (Top) Noise and (bottom) bias in kelvin for a simulated SMOS snapshot of a homogeneous ocean scene at $150 \mathrm{~K}$. Highest values are found in the E-AF-FOV (lower parts near the borders of the image). Color scale ranges from 1.5 (blue) to 3.5 (red) in noise and from -6 (blue) to 6 (red) in bias. (From SMOS end-to-end study, CESBIO.)

available. Additional improvements can be obtained by introducing balancing terms in the cost function to achieve an optimal retrieval [73].

In recent studies, methods have been proposed to reduce the bias by introducing information from Argo floats in the SSS retrieval through an SSS external calibration [67] besides the $\mathrm{T}_{\mathrm{B}}$ calibration described in [71].

\section{CONCLUSIONS AND FUTURE IMPROVEMENTS}

SMOS is the first attempt to measure salinity from space. The technical complexity that prevented us until now from designing a mission with a low-frequency microwave radiometer for global salinity and soil moisture observations at a reasonable spatial resolution has been overcome using a new technological concept: a spaceborne synthetic 
aperture passive instrument. The development of MIRAS and its implementation has allowed construction of an interferometric radiometer with tested performances even above expectations (Table 1).

The mission parameters configuration (satellite height, antenna plane tilt, elements spacing, etc.) have been a consequence of a tradeoff between requirements for soil moisture and ocean salinity measurements. The need for short revisit time and high spatial resolution, imposed by soil moisture science objectives, has a negative impact on what could be the performance of a similar oceanographiconly mission.

The determination of SSS from space is very challenging. The small $\mathrm{T}_{\mathrm{B}}$ range of the ocean emission, the errors associated to the image reconstruction process, and the complex forward modeling (including the use of external information on surface roughness and the correction for sun and galaxy radiation impact) are pushing SMOS salinity retrieval to the limits of its feasibility. However, the simulations made until now considering all the components and constraints of the system indicate that the capability of providing the SSS regular observations (maybe combining SMOS with in situ data) needed to fulfill the science objectives for large-scale oceanography and climate variability can be met. A recent publication [74] demonstrates that in the region of the Amazon plume, SSS can be retrieved from a spaceborne radiometer operating at higher C- and X-band frequencies (AMSR-E) than L-band. Despite an at least ten times weaker sensitivity to salinity than the future SMOS radiometer, AMSR-E retrieved SSS accuracy (1.5 pss) encouragingly is shown to be in line with the expected SMOS accuracy (0.1 pss).

After this exploratory mission, ESA is envisaging a series of operational satellites (SMOS operational system, SMOSops) that could continue the overall soil moisture and ocean salinity data provision following the same technological approach, but with several improvements on different elements. One of the main drawbacks of SMOS for salinity retrieval is the unavailability of ocean surface roughness measurements collocated with radiometer data acquisition. This is faced in SMOSops by the use of two additional payloads: a one-dimensional full-polarization interferometric radiometer (FPIR) at a different frequency and an experimental GNSS-R reflectometry instrument. FPIR shall provide information about the effective wind speed at a resolution of about $100 \mathrm{~km}$, while GNSS-R shall deliver, through a methodology still under development, mean square slope with $20 \mathrm{~km}$ spatial resolution but sparse coverage (depending on the available number of satellites of the Global Navigation Satellite Systems). Both instruments will provide collocated observations with the MIRAS-2 main payload, which should lead to enhanced salinity retrievals. Moreover, the L-band receivers on MIRAS-2 planned for SMOSops will incorporate parallel $\mathrm{H}$ - and V-channels and higher sampling rate, which altogether will bring a factor of two improvement in the radiometric sensitivity, crucial for salinity measurements. Finally, the spacing between elements in SMOSops will be smaller than in SMOS, translating into a wider alias-free field of view, which will allow having more and better quality observations for averaging over time and space to meet even more stringent future SSS requirements.

\section{Acknowledgment}

This paper summarizes the effort made by many international scientific, technological and industrial teams throughout Europe. Detailed comments from three reviewers helped in improving the quality and clarity of this paper.

\section{REFERENCES}

[1] W. S. Broecker, "The great conveyor belt," Oceanography, vol. 4, pp. 79-89, 1991.

[2] M. Latif, "Tropical Pacific/Atlantic Ocean interactions at multi-decadal time scales," Geophys. Res. Lett., vol. 28, pp. 539-542, Feb. 2001

[3] J. Ballabrera-Poy, R. Murtugudde, and A. J. Busalacchi, "On the potential impact of sea surface salinity observations on ENSO predictions," J. Geophys. Res., vol. 107, Sep.-Nov. 2002.

[4] R. Lukas and E. Lindstrom, "The mixed layer of the Western Equatorial Pacific Ocean," J. Geophys. Res., vol. 96, pp. 3343-3357, 1991.

[5] C. Maes, J. Picaut, and S. Belamari, "Salinity barrier layer and onset of El Nino in a Pacific coupled model," Geophys. Res. Lett., vol. 29, Dec. 2002.

[6] C. Henocq, J. Boutin, F. Petitcolin, G. Reverdin, S. Arnault, and P. Lattes, "Vertical variability of near-surface salinity in the tropics: Consequences for L-band radiometer calibration and validation," J. Atmos. Ocean. Technol., to be published.

[7] J. Ballabrera-Poy, B. Mourre, E. García-Ladona, A. Turiel, and J. Font,
"Linear and nonlinear T-S models for the Eastern North Atlantic from Argo data: Role of surface salinity observations," Deep-Sea Res. I, vol. 56, pp. 1605-1614, 2009.

[8] Y. H. Kerr, P. Waldteufel, J. P. Wigneron, J. M. Martinuzzi, J. Font, and M. Berger, "Soil moisture from space: The Soil Moisture and Ocean Salinity (SMOS) mission," IEEE Trans. Geosci. Remote Sens., vol. 39, pp. 1729-1735, 2001.

[9] J. Font, G. S. E. Lagerloef, D. M. Le Vine, A. Camps, and O. Z. Zanifé, "The determination of surface salinity with the European SMOS space mission," IEEE Trans. Geosci. Remote Sens., vol. 42, pp. 2196-2205, 2004.

[10] Y. H. Kerr, P. Waldteufel, J. P. Wigneron, F. Cabot, J. Boutin, M. J. Escorihuela, J. Font, N. Reul, C. Gruhier, S. Juglea, S. Delwart, M. Drinkwater, A. Hahne, and M. Martín-Neira, "The SMOS mission: A new tool for monitoring key elements of the global water cycle," Proc. IEEE, to be published.

[11] G. S. E. Lagerloef, "Satellite measurements of salinity," in Encycl. Ocean Sci., J. Steele, S. Thorpe, and K. Turekian, Eds. London, U.K.: Academic, 2001, pp. 2511-2516.
[12] C. T. Swift and R. E. McIntosh, "Considerations for microwave remote sensing of ocean surface salinity," IEEE Trans. Geosci. Remote Sens., vol. GRS-21, pp. 480-491, 1983.

[13] S. H. Yueh, R. West, W. J. Wilson, F. K. Li, E. G. Njoku, and Y. Rahmat-Samii, "Error sources and feasibility for microwave remote sensing of ocean surface salinity,' IEEE Trans. Geosci. Remote Sens., vol. 39, pp. 1049-1060, 2001.

[14] Y. H. Kerr, K. Fukami, N. Skou, M. A. Srokosz, G. S. E. Lagerloef, J. M. Goutoule, D. M. L. Vine, M. Martín-Neira, W. Marczewski, B. Laursen, J. Gazdewich, J. Barà, and A. Camps, Proceedings of the Consultative Meeting on Soil Moisture and Ocean Salinity Measurement Requirements and Radiometer Techniques (SMOS), Noordwijk, The Netherlands, 1995, ESA WPP-87.

[15] C. S. Ruf, C. T. Swift, A. B. Tanner, and D. M. Le Vine, "Interferometric synthetic aperture microwave radiometry for the remote sensing of the Earth," IEEE Trans. Geosci. Remote Sens., vol. 26, pp. 597-611, Sep. 1988.

[16] D. M. Le Vine, J. B. Zaitzeff, E. J. D’Sa, J. L. Miller, C. Swift, and M. Goodberlet, 
"Sea surface salinity: Toward an operational remote-sensing system," in Satellites, Oceanography and Society, D. Halpern, Ed. Amsterdam, The Netherlands: Elsevier, 2000, pp. 321-335.

[17] D. M. LeVine and J. C. Good, "Aperture synthesis for microwave radiometers in space," NASA Tech. Memo. 85033, 1983.

[18] I. Corbella, N. Duffo, M. Vall-llossera, A. Camps, and F. Torres, "The visibility function in interferometric aperture synthesis radiometry," IEEE Trans. Geosci. Remote Sens. vol. 42, pp. 1677-1682, 2004.

[19] M. Martín-Neira, S. Ribó, and A. J. Martín-Polegre, "Polarimetric mode of MIRAS," IEEE Trans. Geosci. Remote Sens., vol. 40, pp. 1755-1768, Aug. 2002.

[20] J. Randa, J. Lahtinen, A. Camps, A. J. Gasiewski, M. Hallikainen, D. M. Le Vine, M. Martín-Neira, J. Piepmeier P. W. Rosenkranz, C. S. Ruf, J. Shiue, and N. Skou, "Recommended terminology for microwave radiometry," National Institute of Standards and Technology, Gaithersburg, MD [Online]. Available: http://www.boulder.nist. gov/div818/81801/Noise/publications/ TN1551.pdf

[21] P. J. Napier, A. R. Thompson, and R. D. Ekers, "The very large array: Design and performance of a modern synthesis radio telescope," Proc. IEEE, vol. 71, pp. 1295-1320, 1983.

[22] A. Camps, "Application of interferometric radiometry to earth observation," Ph.D. dissertation, Univ. Politècnica de Catalunya, 1996, pp. 325. [Online]. Available: http:// www.tdx.cesca.es/TDX-1020104-091741/

[23] A. Camps, J. Barà, I. Corbella, and F. Torres, "The processing of hexagonally sampled signals with standard rectangular techniques: Application to 2-D large aperture synthesis interferometric radiometers," IEEE Trans. Geosci. Remote Sens., vol. 35, pp. 183-190, Jan. 1997.

[24] P. Waldteufel, J. Boutin, and Y. Kerr, "Selecting an optimal configuration for the Soil Moisture and Ocean Salinity mission," Radio Sci., vol. 38, p. 8051, 2003.

[25] A. Camps, M. Vall-llossera, I. Corbella, N. Duffo, and F. Torres, "Improved image reconstruction algorithms for aperture synthesis radiometers," IEEE Trans. Geosci. Remote Sens., vol. 46, pp. 146-158, Jan. 2008.

[26] M. Martín-Neira, M. Suess, J. Kainulainen, and F. Martin-Porqueras, "The flat target transformation," IEEE Trans. Geosci. Remote Sens., vol. 46, pp. 613-620, Mar. 2008.

[27] A. Camps, M. Vall-llossera, N. Duffo, I. Corbella, F. Torres, and V. Barrena, "Sun effects in 2-D aperture synthesis radiometry imaging and their cancellation," IEEE Trans. Geosci. Remote Sens., vol. 42, pp. 1161-1167, Jun. 2004.

[28] I. Corbella, F. Torres, A. Camps, N. Duffo, and M. Vall-llossera, "Brightness-temperature retrieval methods in synthetic aperture radiometers," IEEE Trans. Geosci. Remote Sens., vol. 47, pp. 285-294, Jan. 2009.

[29] A. B. Tanner and C. T. Swift, "Calibration of a synthetic aperture radiometer," IEEE Trans. Geosci. Remote Sens., vol. 31, pp. 257-267, Jan. 1993.

[30] E. Anterrieu, "A resolving matrix approach for synthetic aperture imaging radiometers," IEEE Trans. Geosci. Remote Sens., vol. 42, pp. 1649-1656, 2004.

[31] E. Anterrieu, P. Waldteufel, and A. Lannes, "Apodization functions for 2-D hexagonally sampled synthetic aperture Imaging radiometers," IEEE Trans. Geosci. Remote Sens., vol. 40, pp. 2531-2542, Dec. 2002.

[32] J. Barà, A. Camps, F. Torres, and I. Corbella, "Angular resolution of two-dimensional, hexagonally sampled interferometric radiometers," Radio Sci., vol. 33, pp. 1459-1473, Sep./Oct. 1998.

[33] M. Martín-Neira, "Strip adaptative processing," in Proc. SMOS SAG-5, Noordwijk, The Netherlands, 2001.

[34] E. Anterrieu, B. Picard, M. Martín-Neira, P. Waldteufel, M. Suess, J. L. Vergely, Y. Kerr, and S. Roques, "A strip adaptive processing approach for the SMOS space mission," in Proc. IEEE Int. Geosci. Remote Sens. Symp., Anchorage, AK, 2004, pp. 1922-1925.

[35] A. Camps, I. Corbella, J. Barà, and F. Torres, "Radiometric sensitivity computation in aperture synthesis interferometric radiometry," IEEE Trans. Geosci. Remote Sens., vol. 36, no. 5, p. 1835 , Mar. 1998.

[36] J. B. Hagen and D. T. Farley, "Digital correlation techniques in radio science," Radio Sci., vol. 8, pp. 775-784, 1973.

[37] J. Barà, A. Camps, F. Torres, and I. Corbella, "The correlation of visibilty noise and its impact on the radiometric resolution of an aperture synthesis radiometer," IEEE Trans. Geosci. Remote Sens., vol. 38, pp. 2423-2426, Sep. 2000.

[38] R. Butora and A. Camps, "Noise maps in aperture synthesis radiometric images due to cross-correlation of visibility noise," Radio Sci., vol. 38, Jul. 2003.

[39] F. Torres, I. Corbella, A. Camps, J. Barà, N. Duffo, M. Vall-llossera, and A. Borges, "Receiver specifications of the MIRAS demonstrator," in Proc. Conf. Sensors, Syst., Next-Gen. Satellites IV, Barcelona, Spain, 2000, pp. 291-298.

[40] A. Camps, J. Barà, F. Torres, I. Corbella, and J. Romeu, "Impact of antenna errors on the radiometric accuracy of large aperture synthesis radiometers," Radio Sci., vol. 32, pp. 657-668, Mar./Apr. 1997.

[41] F. Torres, A. Camps, J. Barà, I. Corbella, and R. Ferrero, "On-board phase and modulus calibration of large aperture synthesis radiometers: Study applied to MIRAS," IEEE Trans. Geosci. Remote Sens., vol. 34, pp. 1000-1009, Jul. 1996.

[42] J. Barà, A. Camps, I. Corbella, and F. Torres, "Specification of channel filters for an interferometric radiometer," Radio Sci., vol. 36, pp. 97-106, Jan./Feb. 2001.

[43] M. A. Brown, F. Torres, I. Corbella, and A. Colliander, "SMOS calibration," IEEE Trans. Geosci. Remote Sens., vol. 46, pp. 646-658, 2008.

[44] A. Camps, J. Barà, F. Torres, and I. Corbella, "Extension of the CLEAN technique to the microwave imaging of continuous thermal sources by means of aperture synthesis radiometers," J. Electromagn. Wave, vol. 12, pp. 311-313, 1998.

[45] J. Font, J. Boutin, N. Reul, P. Waldteufel, C. Gabarró, S. Zine, J. Tenerelli, F. Petitcolin, and J. L. Vergely, "An iterative convergence algorithm to retrieve sea surface salinity from SMOS L-band radiometric measurements," in Proc. IEEE Int. Geosci. Remote Sens. Symp., Denver, CO, 2006, pp. 1689-1692.

[46] S. Zine, J. Boutin, J. Font, N. Reul, P. Waldteufel, C. Gabarró, J. Tenerelli, F. Petitcolin, J. L. Vergely, M. Talone, and S. Delwart, "Overview of the SMOS sea surface salinity prototype processor,"
IEEE Trans. Geosci. Remote Sens., vol. 46 pp. 621-645, Mar. 2008.

[47] L. A. Klein and C. T. Swift, "Improved model for dielectric constant of sea-water at microwave frequencies," IEEE Trans. Antennas Propag., vol. AP-25, pp. 104-111, 1977.

[48] S. Blanch and A. Aguasca, "Seawater dielectric permittivity model from measurements at L-band," in Proc. IEEE Int. Geosciences and Remote Sensing Symp., Anchorage, AK, 2004.

[49] R. H. Lang, C. Utku, J. Janiczek, Y. Tarkocin, and D. M. Le Vine, "Accurate L-band measurements of the dielectric constant of seawater," in IEEE Int. Geosci. Remote Sens. Symp., Barcelona, Spain, 2007 pp. 5255-5257.

[50] E. P. Dinnat, J. Boutin, G. Caudal, and J. Etcheto, "Issues concerning the sea emissivity modeling at $\mathrm{L}$ band for retrieving surface salinity," Radio Sci., vol. 38, p. 8060 , 2003.

[51] C. Gabarró, J. Font, A. Camps, M. Vall-llossera, and A. Julià, "A new empirical model of sea surface microwave emissivity for salinity remote sensing," Geophys. Res. Lett., vol. 31, p. L01309, 2004.

[52] E. P. Dinnat, J. Boutin, G. Caudal, J. Etcheto, and P. Waldteufel, "Influence of sea surface emissivity model parameters at L-band for the estimation of salinity," Int. J. Remote Sens., vol. 23, pp. 5117-5122, 2002.

[53] J. T. Johnson and M. Zhang, "Theoretical study of the small slope approximation for ocean polarimetric thermal emission," Wave Random Complex, vol. 37, pp. 2305-2316, 1999.

[54] C. Gabarró, J. Font, J. L. Miller, A. Camps, D. Burrage, J. Wesson, and A. R. Piola, "The use of a semi-empirical emissivity model for a rough estimation of sea surface salinity from an airborne radiometer," Sci. Mar., vol. 72, pp. 329-336, 2008.

[55] A. Camps, J. Font, M. Vall-llossera, C. Gabarró, I. Corbella, N. Duffo, F. Torres, S. Blanch, A. Aguasca, R. Villarino, L. Enrique, J. Miranda, J. J. Arenas, A. Julià, J. Etcheto, V. Caselles, A. Weill, J. Boutin, S. Contardo, R. Niclòs, R. Rivas, S. C. Reising, P. Wursteisen, M. Berger, and M. Martín-Neira, "The WISE 2000 and 2001 field experiments in support of the SMOS mission: Sea surface L-band brightness temperature observations and their application to sea surface salinity retrieval," IEEE Trans. Geosci. Remote Sens. vol. 42, pp. 804-823, 2004.

[56] A. Camps, M. Vall-llossera, R. Villarino, N. Reul, B. Chapron, I. Corbella, N. Duffo, F. Torres, J. Miranda, R. Sabia, S. Monerris, and R. Rodríguez, "The emissivity of foam-covered water surface at L-band: Theoretical modeling and experimental results from the FROG 2003 field experiment," IEEE Trans. Geosci. Remote Sens. vol. 43, pp. 925-937, May 2005.

[57] N. Reul and B. Chapron, "A model of sea-foam thickness distribution for passive microwave remote sensing applications," J. Geophys. Res., vol. 108, p. 3321, 2003.

[58] A. Camps, J. Font, M. Vall-Llossera, I. Corbella, N. Duffo, F. Torres, S. Blanch, A. Aguasca, R. Villarino, C. Gabarró, L. Enrique, J. Miranda, R. Sabia, and M. Talone, "Determination of the sea surface emissivity at L-band and application to SMOS salinity retrieval algorithms: Review of the contributions of the UPC-ICM,” Radio Sci., vol. 43, Jun. 2008. 
[59] N. Skou and D. Hoffman-Bang, "L-band radiometers measuring salinity from space: Atmospheric propagation effects," IEEE Trans. Geosci. Remote Sens., vol. 43, pp. 2210-2217, Oct. 2005.

[60] N. Skou, "Faraday rotation and L-band oceanographic measurements," Radio Sci., vol. 38, p. 8059, 2003.

[61] P. Waldteufel, N. Floury, E. P. Dinnat, and G. Caudal, "Ionospheric effects for L-band 2-D interferometric radiometry," IEEE Trans. Geosci. Remote Sens., vol. 42, pp. 105-118, 2004.

[62] A. Camps, I. Corbella, M. Vall-llossera, N. Duffo, F. Torres, R. Villarino, L. Enrique, F. Julbe, J. Font, A. Julià, C. Gabarró, J. Etcheto, J. Boutin, A. Weill, E. Rubio, V. Caselles, P. Wursteisen, and M. Martín-Neira, "L-band sea surface emissivity: Preliminary results of the WISE-2000 campaign and its application to salinity retrieval in the SMOS mission," Radio Sci., vol. 38, p. 8071, 2003.

[63] J. E. Tenerelli, N. Reul, A. A. Mouche, and B. Chapron, "Earth-viewing L-band radiometer sensing of sea surface scattered celestial sky radiation-Part I: General characteristics," IEEE Trans. Geosci. Remote Sens., vol. 46, pp. 659-674, Mar. 2008.

[64] N. Reul, J. E. Tenerelli, N. Floury, and B. Chapron, "Earth-viewing L-band radiometer sensing of sea surface scattered celestial sky radiation - Part II: Application to SMOS," IEEE Trans. Geosci. Remote Sens., vol. 46, pp. 675-688, Mar. 2008.

[65] N. Reul, J. Tenerelli, B. Chapron, and P. Waldteufel, "Modeling sun glitter at L-band for the sea surface salinity remote sensing with SMOS," IEEE Trans. Geosci. Remote Sens., vol. 45, pp. 2073-2087, 2007.

[66] S. Zine, J. Boutin, P. Waldteufel, J. L. Vergely, T. Pellarin, and P. Lazure, "Issues about retrieving sea surface salinity in coastal areas from SMOS data," IEEE Trans. Geosci. Remote Sens., vol. 45, pp. 2061-2072, Jul. 2007.

[67] M. Talone, A. Camps, B. Mourre, R. Sabia, M. Vall-llossera, J. Gourrion, C. Gabarró, and J. Font, "Simulated SMOS level 2 and 3 products: The effect of introducing ARGO data in the processing chain and its impact on the error induced by the vicinity of the coast," IEEE Trans. Geosci. Remote Sens., vol. 47, pp. 3041-3050, 2009.

[68] C. J. Koblinsky, P. Hildebrand, D. LeVine, F. Pellerano, Y. Chao, W. Wilson, S. Yueh, and G. Lagerloef, "Sea surface salinity from space: Science goals and measurement approach," Radio Sci., vol. 38, p. 8064, 2003.

[69] G. Lagerloef, F. R. Colomb, D. Le Vine, F. Wentz, S. Yueh, C. Ruf, J. Lilly, J. Gunn, Y. Chao, A. deCharon, G. Feldman, and C. Swift, "The Aquarius/SAC-D mission designed to meet the salinity remote sensing challenge," Oceanography, vol. 21, pp. 68-81, Mar. 2008.

[70] J. Boutin, P. Waldteufel, N. Martin, G. Caudal, and E. Dinnat, "Surface salinity retrieved from SMOS measurements over the global ocean: Imprecisions due to sea surface roughness and temperature uncertainties," J. Atmos. Ocean. Technol., vol. 21, pp. 1432-1447, 2004.

[71] A. Camps, M. Vall-llossera, L. Batres, F. Torres, N. Duffo, and I. Corbella, "Retrieving sea surface salinity with multi-angular L-band brightness temperatures: Improvement by spatio-temporal averaging," Radio Sci., vol. 40, p. RS2003, 2005.

[72] R. Sabia, A. Camps, M. Vall-llossera, and M. Talone, "Extended ocean salinity error budget analysis within the SMOS mission," in Proc. IEEE Int. Geosci. Remote Sens. Symp., Boston, MA, 2008.

[73] C. Gabarró, M. Portabella, M. Talone, and J. Font, "Towards an optimal SMOS ocean salinity inversion algorithm," IEEE Geosci. Remote Sens. Lett., vol. 6, pp. 509-513, 2009.

[74] N. Reul, S. Saux-Picart, B. Chapron, D. Vandemark, J. Tournadre, and J. Salisbury, "Demonstration of ocean surface salinity microwave measurements from space using AMSR-E data over the Amazon plume," Geophys. Res. Lett., vol. 36, p. L13607, 2009.

\section{ABOUT THE AUTHORS}

Jordi Font received the B.Sc. and Ph.D. degrees in physics from the University of Barcelona, Barcelona, Spain, in 1973 and 1986, respectively.

$\mathrm{He}$ is a Senior Researcher with the Physical Oceanography Department, Institut de Ciències del Mar, Spanish Research Council, Consejo Superior de Investigaciones Cientificas, Barcelona. He is the author or coauthor of 125 published papers and 300 communications to scientific symposia. $\mathrm{He}$ is the Adviser of nine Ph.D. dissertations. He

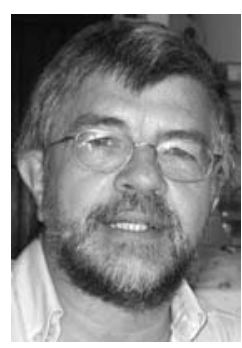
has been Principal Investigator in several Spanish and European research contracts. He is currently the Co-Lead Investigator for ocean salinity in the European Space Agency SMOS mission. He is Chairman of Physics and Climate of the Ocean Committee of the International Commission for the Scientific Exploration of the Mediterranean Sea. His main research activities include the study of ocean remote sensing (determination of sea surface salinity by microwave radiometry), physical oceanography of the Mediterranean Sea (water masses, circulation, and climate change), ocean circulation (operational measurements of ocean currents, technological improvements), and mesoscale dynamics (fronts, eddies, topographic interactions, physical-biological processes coupling). He is a participant in 42 oceanographic campaigns.

Dr. Font is a member of several international societies and committees.

Adriano Camps (Senior Member, IEEE) was born in Barcelona, Spain, in 1969. He received the bachelor's and Ph.D. degrees in telecommunications engineering from the Universitat Politècnica de Catalunya (UPC), Barcelona, Spain, in 1992 and 1996, respectively.

In 1991-1992, he was with ENS des Télécommunications de Bretagne, France, with an Erasmus Fellowship. In 1993, he joined the Electromagnetics and Photonics Engineering group, Department of Signal Theory and Communications, UPC, as an Assistant
Professor. Since 1997, he has been an Associate Professor and since 2007 a full Professor. In 1999, he was on sabbatical leave with the Microwave Remote Sensing Laboratory, University of Massachusetts, Amherst. His research interests are focused in microwave remote sensing, with special emphasis in microwave radiometry by aperture synthesis techniques and the use of global navigation satellite signals as signals of opportunity when reflected over the ocean and land to infer sea state and soil moisture information (GNSS-R). Since 1993, he has carried out numerous studies for ESA's SMOS Earth Explorer Mission. He has published more than 75 peer-reviewed journal papers and 170 conference papers. He has received four patents. He was Chair of $\mu$ Cal'O1 and Technical Committee Chair of IGARSS 2007. He is an Associate Editor of Radio Science.

Dr. Camps received the second national award of university studies (1993); the INDRA award from the Spanish Association of Telecommunication Engineering for the best Ph.D. in remote sensing (1997); the extraordinary Ph.D. award from UPC (1999); the Research Distinction from the Generalitat de Catalunya for contributions to microwave passive remote sensing (2002); the European Young Investigator award (2004); and 13 (2008) and ICREA Academia (2009) mentions for outstanding research. As a member of the Microwave Radiometry Group at UPC, he received the 1st Duran Farell (2000) and Ciutat de Barcelona (2001) awards for Technology Transfer, and the Salvà i Campillo Award (2004) from the Professional Association of Telecommunication Engineers of Catalonia for the most innovative research project. He is an Associate Editor of the IeEe transactions on Geoscience and Remote Sensing and past Editor of the IEeE Geoscience And Remote Sensing Newsletter (20032006). He was the President-Founder of the IEEE Geoscience and Remote Sensing Society Chapter in Spain. 
Andrés Borges graduated in electrical engineering from the Polithecnic Universisty of Valencia, Spain, in 1989. He received a degree in business administration from UNED, Spain, and the M.B.A. degree from the Instituto de Empresa, Spain.

He was a Software Engineer with the European Space Agency, specializing in software development for space robotics. In 1992, he joined EADS CASA Espacio, Madrid, Spain, and he worked during six years in several space projects as a

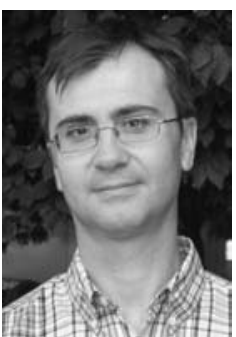
Software and System Engineer. In 1998, he became Project Manager of the MIRAS Demonstrator Project, a technology development project for SMOS. Later, he continued as Project Manager throughout the development phases of the SMOS payload, MIRAS. At present, he is Project Manager of INGENIO, the first Spanish optical satellite.

Manuel Martín-Neira (Senior Member, IEEE) received the M.S. and Ph.D. degrees in telecommunication engineering from the School of Telecommunication Engineering, Universitat Politècnica de Catalunya (UPC), Barcelona, Spain, in 1986 and 1996, respectively.

He received a fellowship to work on radiometry at the European Space Research and Technology Center, Noordwijk, The Netherlands, in 1988. From 1989 to 1992, he was with GMV, a Spanish firm,

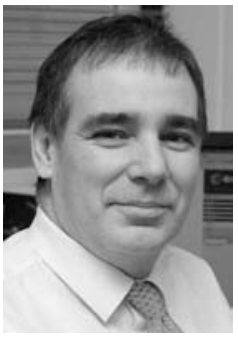
where he was responsible for several projects for the European Space Agency (ESA) related to GPS spacecraft navigation with applications to precise landing and attitude determination. Since 1992, with ESA, he has been in charge of radiometer activities within the Payload, Equipment and Technology Section. During this period, he has also developed new concepts for constellations of small satellites for Earth observation. In particular, he holds several patents related to aperture synthesis radiometry and on the PARIS concept for the use of GNSS signals reflected from the ocean. He has been the Instrument Principal Engineer of ESA's Soil Moisture and Ocean Salinity Earth Explorer Opportunity Mission since 2001.

Dr. Martín-Neira is a member of the Academie des Technologies of France. He received the Confirmed Inventor Award from the Director of ESA in 2002.

Jacqueline Boutin received the Ph.D. degree in physical methods in remote sensing from the University Paris VII, Paris, France, in 1990.

She is currently a Research Scientist with the Centre National de la Recherche Scientifique, Laboratoire d'Océanographie et du ClimatExpérimentation et Approches Numériques, Paris. She has widely studied the validity of remotely sensed wind speeds and the ocean/atmosphere exchange of $\mathrm{CO}_{2}$ at large scale using both satellite

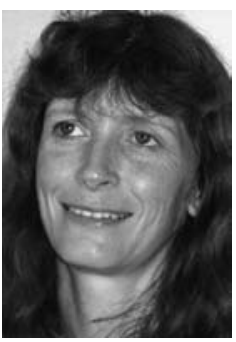
(wind speeds, sea surface temperature, and ocean color) and in situ data (in particular, carbon-interface ocean-atmosphere autonomous drifters). Since 1999, she has been involved in the preparation of the SMOS mission. She participated in the development of an L-band sea surface emissivity model and in several airborne campaigns (WISE and Eurostarrs). She is a member of the European Space Agency Expert Support Laboratories that define and validate the processing of SMOS Level 2 measurements for the retrieval of sea surface salinity.
Nicolas Reul received the B.S. degree in marine science engineering from Toulon University, La Garde, France, in 1993 and the Ph.D. degree in fluid mechanics from the University of AixMarseille II, Marseille, France, in 1998.

$\mathrm{His}$ fields of interest are in the air-sea interaction processes, boundary layer turbulence, surface gravity waves, upper ocean dynamics, breaking waves dynamics, ocean surface remote sensing, and, in particular, sea surface salinity

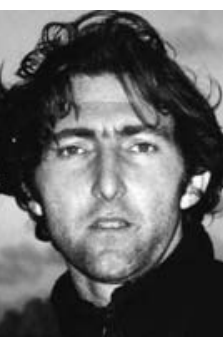
remote sensing with microwave radiometry. He was with the Department of Applied Marine Physics, Rosenstiel School of Marine and Atmospheric Science, University of Miami, FL, for two years as a Postdoctoral Research Associate. He is currently a Research Scientist with the Laboratoire d'Océanographie Spatiale, Institut Français de Recherche et d'Exploitation de la Mer, Plouzané, France, where he is responsible for a project focussed on sea surface salinity remote sensing. He provides scientific support to the development of ESA and CNES SMOS salinity Level 2, 3, and 4 product ground segment development. He is also a member of the SMOS mission Science Advisory Group for ESA. He has experience in applied mathematics, physical oceanography, electromagnetic wave theory, and its application to ocean remote sensing.

Yann H. Kerr (Senior Member, IEEE) received the engineering degree from Ecole Nationale Supérieure de l'Aéronautique et de l'Espace, France, the M.Sc. degree in electrical and electronic engineering from Glasgow University, Glasgow, Scotland, U.K., and the Ph.D. degree from Université Paul Sabatier, France.

From 1980 to 1985 , he was with the Centre National de la Recherche Scientifique. In 1985, he joined LERTS; for which he was Director in 1993-

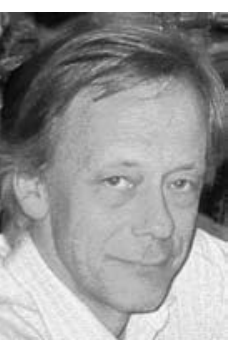
1994. He spent 19 months with the Jet Propulsion Laboratory, Pasadena, CA, in 1987-1988. He has been with CESBIO since 1995 (Deputy Director and Director since 2007). His fields of interest are in the theory and techniques for microwave and thermal infrared remote sensing of the Earth, with emphasis on hydrology, water resources management, and vegetation monitoring. He has been involved with many space missions. He was an EOS principal investigator (interdisciplinary investigations) and PI and precursor of the use of the SCAT over land. In 1990, he began to work on the interferometric concept applied to passive microwave earth observation and was subsequently the Science Lead on the MIRAS project for ESA with Matra Marconi Space and Observatoire Midi Pyrénées. He was also a Co-Investigator on IRIS, OSIRIS, and HYDROS for NASA. He was Science Advisor for MIMR and a Co-Investigator on AMSR. In 1997, he first proposed the natural outcome of the previous MIRAS work with what was to become the SMOS Mission, which was eventually selected by ESA in 1999 with him as the SMOS mission LeadInvestigator and Chair of the Science Advisory Group. He is also in charge of SMOS science activities coordination in France. He has organized all the SMOS Science workshops. 
Achim Hahne graduated in atmospheric chemistry from the Nuclear Research Centre, Jülich, Germany. He received the Ph.D. degree in material science from Aachen Technical University, Germany.

In 1983, he joined the European Space Agency. After initial positions with the Space Science and the Technical Directorates, he joined the Earth Observation Programmes Directorate, where he worked on the ERS 1/2, ENVISAT, and METOP

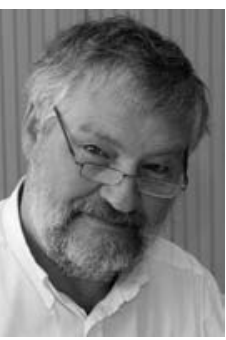

Susanne Mecklenburg received the master's degree in hydrology from the Technical university of Dresden, Germany, and the Ph.D. degree in atmospheric science from the Swiss Institute of Technology, Zurich, Switzerland.

She has been the SMOS Mission Manager since 2007

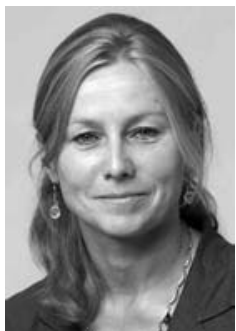

Projects. He has been the SMOS Project Manager since 2002. 